Supporting Information:

\title{
Rhodium-Catalyzed Asymmetric Ring Opening of Oxabicyclic Alkenes with Organoboronic Acids
}

Mark Lautens*, Chris Dockendorff, Keith Fagnou, and Adrianna Malicki

Davenport Laboratories, Department of Chemistry, University of Toronto, Toronto, Ontario, Canada M5H 3H6.

\section{Methods}

All reactions were carried out under nitrogen atmosphere with magnetic stirring. THF was distilled under nitrogen atmosphere from benzophenone ketyl prior to use. Boronic acids were obtained from Aldrich and used without further purification. Ethylene glycol esters of boronic acids were synthesized by heating phenylboronic acid (1 eq.) and ethylene glycol (1 eq.) in toluene, and distilling off the toluene/water. The resulting liquid was purified by Kugelrohr distillation. Oxabicycles $\mathbf{1}^{1}, \mathbf{4 a}, \mathbf{4} \mathbf{b}^{2}, \mathbf{9} \mathbf{a}^{3}$, and $\mathbf{9} \mathbf{b}^{4}$ were synthesized according to literature procedures. Solvents and solutions were transferred using standard inert atmosphere techniques. Analytical thin layer chromatography was performed with Silicycle ${ }^{\mathrm{TM}}$ normal phase $0.25 \mathrm{~mm}$ Aluminum-backed TLC plates. Visualization was accomplished with $254 \mathrm{~nm}$ UV light and ethanolic anisaldehyde or aqueous potassium permanganate solutions. Purification of reaction products was done by flash chromatography with Silicycle ${ }^{T M}$ Ultra-Pure 230-400 mesh silica gel.

${ }^{1} \mathrm{H}$ NMR spectra were recorded at 300 or $400 \mathrm{MHz}$, and ${ }^{13} \mathrm{C}$ NMR spectra (proton-decoupled) were recorded at 75 or $100 \mathrm{MHz}$, using Varian spectrometers and solvent as the internal standard. ${ }^{19} \mathrm{~F}$ NMR was recorded at $282 \mathrm{MHz}$ with chemical shifts relative to $\mathrm{CFCl}_{3}$ (internal standard). Spectral features are tabulated in the following order: chemical shift $(\delta, \mathrm{ppm})$; number of protons; multiplicity (s-singlet, d-doublet, t-triplet, q-quartet, m-complex multiplet); coupling constants $(\mathrm{J}, \mathrm{Hz})$. IR spectra were obtained using a Perkin-Elmer Spectrum 1000 FT-IR spectrometer as a neat film on a $\mathrm{NaCl}$ plate. High resolution mass spectra were obtained from a VG 70-250S (double-focusing) mass spectrometer at $70 \mathrm{eV}$. Melting points were taken on a Fisher-Johns melting point apparatus and are uncorrected. HPLC analysis was performed with an Agilent 1100 series HPLC with photodiode array and Chiracel chiral columns with Uniguard 
pre-column filters. Optical rotations were measured in a $10 \mathrm{~cm}$ cell with a Perkin-Elmer $243 \mathrm{~B}$ polarimeter with sodium lamp and are reported as follows: $[\alpha]_{\mathrm{D}}{ }^{\mathrm{T}} \mathrm{C}(\mathrm{c}=\mathrm{g} / 100 \mathrm{~mL}$, solvent $)$.

\section{Experimental Procedures}

Characterization details for compounds made with the following reactions are given in Section

3.

Procedure for the preparation of compound 2:

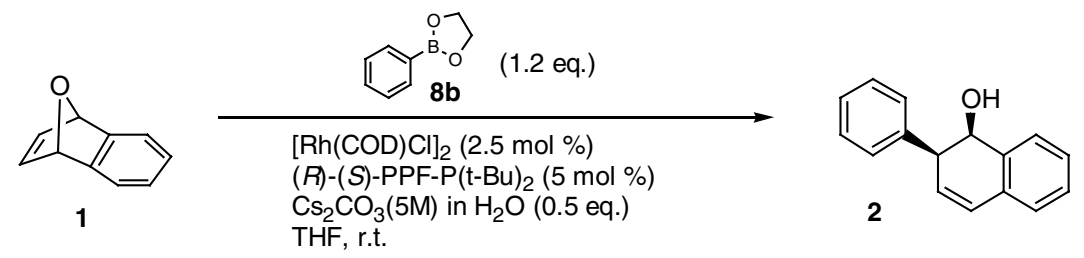

A $10 \mathrm{~mL}$ flask was charged with $[\mathrm{Rh}(\mathrm{COD}) \mathrm{Cl}]_{2}(4.2 \mathrm{mg}, 0.0085 \mathrm{mmol}),(R)-(S)-\mathrm{PPF}-$ $\mathrm{P}(\mathrm{t}-\mathrm{Bu})_{2}$ ligand 3 (9.4 mg, $\left.0.0173 \mathrm{mmol}\right)$, and oxabenzonorbornadiene 1 (50 mg, $0.347 \mathrm{mmol}$ ). A stir bar was added and the flask was sealed and flushed with nitrogen before distilled THF (3 $\mathrm{mL}$ ) was added. Phenylboronic acid (ethylene glycol ester, $62 \mathrm{mg}, 0.419 \mathrm{mmol}$ ) was then added by syringe as a THF solution (with $\sim 0.3 \mathrm{~mL}$ THF), followed by $\mathrm{Cs}_{2} \mathrm{CO}_{3}(5 \mathrm{M})$ in $\mathrm{H}_{2} \mathrm{O}(35 \mu \mathrm{L})$. The reaction was stirred for $14 \mathrm{~h}$, after which time TLC analysis (25\% EtOAc/hexanes) indicated the reaction was complete. The solvent was then evaporated and the crude was dissolved with DCM and transferred onto a glass column packed with silica gel ( 3/4" x 12") and eluted with 5-8\% EtOAc/hexanes. Product 2 was isolated as a colourless oil: $60.3 \mathrm{mg}$, yield $=78 \%$, ee $=93 \%$.

Representative procedure for the preparation of cyclohexenols $\mathbf{5 a - 5 j}$ :

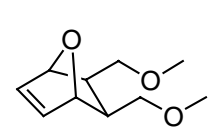

$4 a$

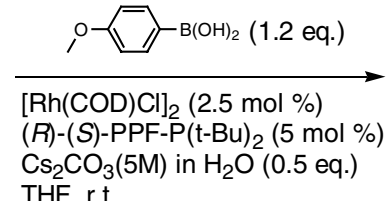

$\mathrm{Cs}_{2} \mathrm{CO}_{3}(5 \mathrm{M})$ in $\mathrm{H}_{2} \mathrm{O}$ (0.5 eq.)

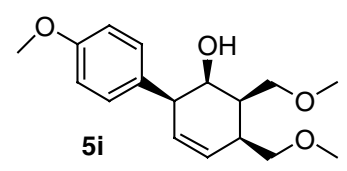

A $5 \mathrm{~mL}$ flask was charged with $[\mathrm{Rh}(\mathrm{COD}) \mathrm{Cl}]_{2}(3.3 \mathrm{mg}, 0.0067 \mathrm{mmol}),(R)-(S)-\mathrm{PPF}-\mathrm{P}(\mathrm{t}-$ $\mathrm{Bu})_{2}$ ligand 3 (7.4 mg, $0.0136 \mathrm{mmol}$ ), and 4-methoxyphenylboronic acid (49 $\mathrm{mg}, 0.322 \mathrm{mmol}$ ). A stir bar was added and the flask was sealed and flushed with nitrogen before distilled THF (1 $\mathrm{mL}$ ) was added. Oxabicycle $\mathbf{4 a}(50 \mathrm{mg}, 0.271 \mathrm{mmol})$ was added to the reaction by syringe as a 
THF solution (with $\sim 0.3 \mathrm{~mL}$ THF). $\mathrm{Cs}_{2} \mathrm{CO}_{3}(5 \mathrm{M})$ in $\mathrm{H}_{2} \mathrm{O}\left(27 \mu \mathrm{L}, 0.136 \mathrm{mmol} \mathrm{Cs}_{2} \mathrm{CO}_{3}\right.$ ) was added by syringe and the reaction was stirred for $14 \mathrm{~h}$. The solvent was then evaporated and the crude was dissolved with DCM and transferred onto a glass column packed with silica gel ( 3/4" x 7") and eluted with 5-20\% EtOAc/hexanes. Product 5i was isolated as a colourless oil: $69.1 \mathrm{mg}$, yield $=87 \%$, ee $=96 \%$.

Procedure for the preparation of compound $\mathbf{6}$ :

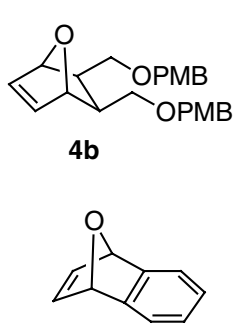

1

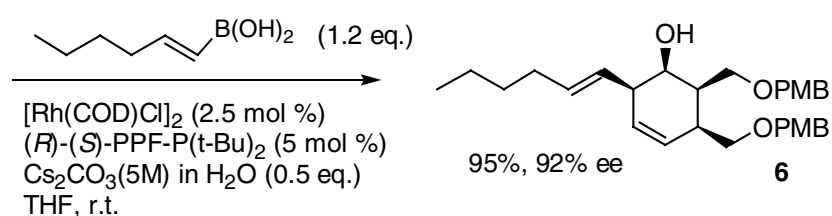
THF, r.t.

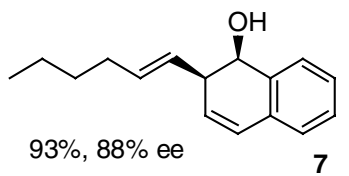

A $10 \mathrm{~mL}$ flask was charged with $[\mathrm{Rh}(\mathrm{COD}) \mathrm{Cl}]_{2}(2.5 \mathrm{mg}, 0.00507 \mathrm{mmol}),(R)-(S)-\mathrm{PPF}-$ $\mathrm{P}(\mathrm{t}-\mathrm{Bu})_{2}$ ligand 3 (5.5 mg, $\left.0.0101 \mathrm{mmol}\right)$, oxabicycle $4 \mathbf{b}$ (80 mg, $\left.0.202 \mathrm{mmol}\right)$, and trans-1hexen-1-ylboronic acid (31 mg, $0.242 \mathrm{mmol}$ ). A stir bar was added and the flask was sealed and flushed with nitrogen before distilled THF $(1 \mathrm{~mL})$ and $\mathrm{Cs}_{2} \mathrm{CO}_{3}(5 \mathrm{M})$ in $\mathrm{H}_{2} \mathrm{O}(20 \mu \mathrm{L}, 0.100 \mathrm{mmol}$ $\mathrm{Cs}_{2} \mathrm{CO}_{3}$ ) were added by syringe. The reaction was stirred for $14 \mathrm{~h}$, after which time TLC analysis (20\% EtOAc/hexanes) indicated the reaction was complete. The solvent was then evaporated and the crude was dissolved with DCM and transferred onto a glass column packed with silica gel ( 1/2" x 7") and eluted with 5-10\% EtOAc/hexanes. Product 6 was isolated as a colourless oil: $92.5 \mathrm{mg}$, yield $=95 \%$, ee $=92 \%$.

Procedure for the preparation of compound 7:

A $10 \mathrm{~mL}$ flask was charged with $[\mathrm{Rh}(\mathrm{COD}) \mathrm{Cl}]_{2}(4.3 \mathrm{mg}, 0.00872 \mathrm{mmol}),(R)-(S)-\mathrm{PPF}-$ $\mathrm{P}(\mathrm{t}-\mathrm{Bu})_{2}$ ligand 3 (9.4 mg, $\left.0.0173 \mathrm{mmol}\right)$, oxabicycle 1 (50 mg, $\left.0.347 \mathrm{mmol}\right)$, and trans-1hexen-1-ylboronic acid (54 mg, $0.422 \mathrm{mmol}$ ). A stir bar was added and the flask was sealed and flushed with nitrogen before distilled THF $(2 \mathrm{~mL})$ and $\mathrm{Cs}_{2} \mathrm{CO}_{3}(5 \mathrm{M})$ in $\mathrm{H}_{2} \mathrm{O}(35 \mu \mathrm{L}, 0.175 \mathrm{mmol}$ $\mathrm{Cs}_{2} \mathrm{CO}_{3}$ ) were added by syringe. The reaction was stirred for $18 \mathrm{~h}$, after which time ${ }^{1} \mathrm{H}$ NMR analysis indicated the reaction was complete. The solvent was then evaporated and the crude 
was dissolved with DCM and transferred onto a glass column packed with silica gel ( 1/2" x 3") and eluted with 4\% EtOAc/hexanes. Product 7 was isolated as a colourless oil: $73.4 \mathrm{mg}$, yield = $93 \%$, ee $=88 \%$.

Procedure for the derivatization of compound 2:

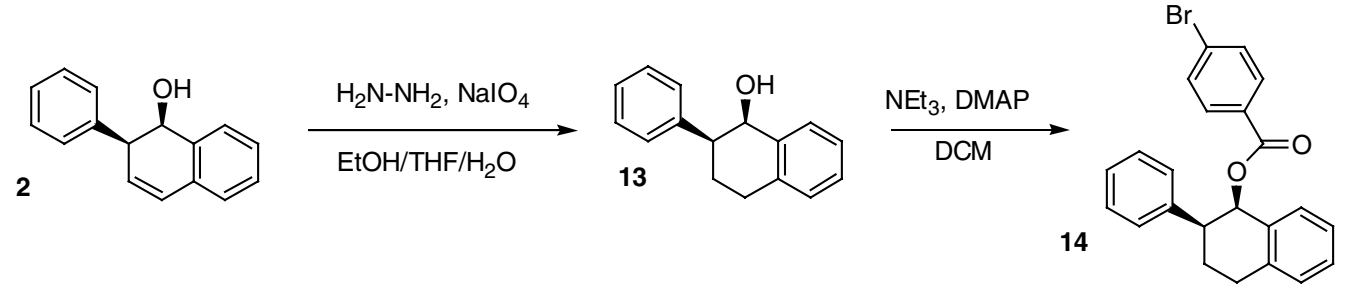

A $100 \mathrm{~mL}$ flask with stir bar containing $2(0.175 \mathrm{~g}, 0.786 \mathrm{mmol})$ was charged with ethanol $(8 \mathrm{~mL})$ and THF $(2.5 \mathrm{~mL})$. The solution was cooled in an ice bath before hydrazine- $\mathrm{H}_{2} \mathrm{O}$ (1.5 mL, $30.9 \mathrm{mmol})$ was added. A hot saturated solution of $\mathrm{NaIO}_{4}(1.65 \mathrm{~g}, 7.73 \mathrm{mmol})$ in water was added dropwise. A water condenser was attached to the flask and the resulting white foam was stirred vigorously in an oil bath at $80^{\circ} \mathrm{C}$. After heating for $1 \mathrm{~h}$ all the foam had dissipated. The reaction was cooled to room temperature and diluted with DCM and brine solution, mixed well, and separated. The aqueous layer was re-extracted twice with DCM, and the combined organics were dried over $\mathrm{MgSO}_{4}$. The crude oil was adsorbed onto a minimum amount of silica gel and transferred onto a column pre-packed with silica gel ( 1/2 x 6"). The desired product was eluted with 2-6\% EtOAc/hexanes and evaporated down to a flaky white solid: $0.128 \mathrm{~g}, 73 \%$ yield.

Product 13 was derivatized by reacting with 4-bromobenzoyl chloride (2 eq.), $\mathrm{NEt}_{3}$ (2 eq.) and 4-dimethylaminopyridine (1 eq.) in DCM (unoptimized procedure). Excess 4bromobenzoyl chloride was hydrolyzed by stirring vigorously the resulting crude solid (after evaporation) in aqueous $\mathrm{NaHCO}_{3}$ solution for $2 \mathrm{~h}$. The aqueous solution was extracted with DCM, and the resulting mixture was purified by filtering through a plug of silica gel (to remove DMAP) and a plug of neutral aluminium oxide (to remove 4-bromobenzoic acid) and eluting with DCM. The resulting pure white solid 14 was recrystallized from hot $\mathrm{CH}_{3} \mathrm{CN}$ to obtain crystals for x-ray analysis. 
Table 1. Initial Ligand Screening. Rh-Catalyzed ARO with Activated Phenylboronate ${ }^{a}$

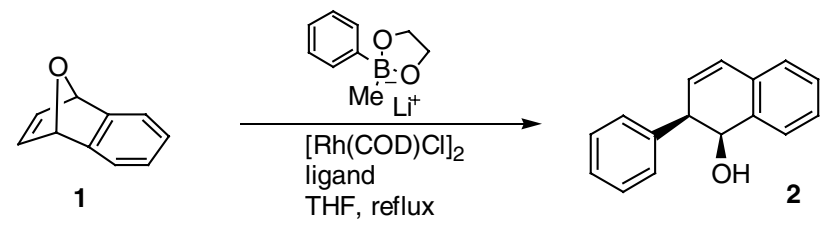

\begin{tabular}{ccccc}
\hline Entry & Ligand & Time & Yield\% $^{\boldsymbol{b}}$ & ee\% $^{\boldsymbol{c}}$ \\
\hline 1 & DPPF & $20 \mathrm{~min}$. & 71 & - \\
3 & BINAP & $30 \mathrm{~min}$. & 43 & 16 \\
2 & tol-BINAP & $30 \mathrm{~min}$. & 53 & 19 \\
4 & ${ }^{\mathrm{i}} \mathrm{Pr}^{-} \mathrm{POX}^{d}$ & $4 \mathrm{~h}$ & n.r. & - \\
5 & PPF-P $^{\mathrm{t}} \mathrm{Bu}_{2}$ & $20 \mathrm{~min}$. & 71 & 67 \\
\hline
\end{tabular}

${ }^{a}$ Conditions: $1 \mathrm{~mol} \%[\mathrm{Rh}(\overline{\mathrm{COD}}) \mathrm{Cl}]_{2}, 2.5 \mathrm{~mol} \%$ ligand, 5 eq. phenylboronic acid derivative, $\sim 1.0 \mathrm{M}$ in THF. ${ }^{b}$ Isolated yield. ${ }^{c}$ Determined by chiral HPLC (Chiracel OD column). ${ }^{d}$ iPr-POX $=$ isopropyl diphenylphosphinophenyl oxazoline.

\section{Characterization}

Absolute and relative configurations of the products in this paper have been assigned by analogy to the structure of compound 14, determined by x-ray structure determination. Further support for the relative stereochemistries is taken from identical or similar compounds described previously in the literature. ${ }^{5}$

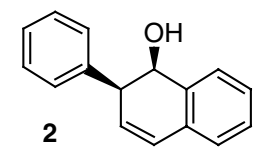

(-)-(1R, 2S)-1,2-Dihydro-2-phenyl-1-naphthol (2): This compound has previously been characterized in racemic form ${ }^{5}$, and an enantioselective synthesis has also been reported. ${ }^{6}$ Note: Compound is light-sensitive, especially in non-polar solvents like hexane and dichloromethane.

Assay of enantiomeric excess: chiral HPLC (Chiracel OD, 2\% isopropanol/hexanes, $1 \mathrm{~mL} / \mathrm{min}$, $\lambda=254 \mathrm{~nm} ; \mathrm{t}_{\mathrm{r}}($ major $)=16.9$ min., $\mathrm{t}_{\mathrm{r}}($ minor $\left.)=31.6 \mathrm{~min}.\right), 92 \%$ ee. $[\alpha]_{\mathrm{D}}^{20}=-168(\mathrm{c}=1.00$, $95 \% \mathrm{EtOH})^{7}$

Absolute configuration: The absolute configuration of $\mathbf{2}$ was determined by $\mathrm{x}$-ray crystallography after conversion to protected tetrahydronaphthalene $\mathbf{1 4 .}$

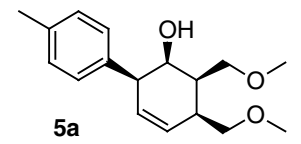

(+)-(1R, 2S, 5S, 6S)-5,6-Bis(methoxymethyl)-2-(4-methylphenyl)-

cyclohex-3-enol (5a): Purified by flash column chromatography ( 3/4" x 7" 
silica gel, eluted with 5-20\% EtOAc/hexanes). Yield $=88 \%$. Colourless oil. $\mathrm{R}_{\mathrm{f}}=0.46(50 \%$ EtOAc/hexanes); IR (film) $v=3419,2892,1515,1458,1448,1097,963,845,791 \mathrm{~cm}^{-1} ;{ }^{1} \mathrm{H}$ NMR $\left(300 \mathrm{MHz}, \mathrm{CDCl}_{3}\right) \delta 7.13(4 \mathrm{H}, \mathrm{s}), 5.85(1 \mathrm{H}, \mathrm{ddd}, J=10.2,3.6,3.2 \mathrm{~Hz}), 5.78(1 \mathrm{H}, \mathrm{dm}, J$ $=11.1 \mathrm{~Hz}), 3.87(1 \mathrm{H}, \mathrm{dm}, J=7.0 \mathrm{~Hz}), 3.63(1 \mathrm{H}, \mathrm{d}, J=9 \mathrm{~Hz}), 3.57(2 \mathrm{H}, \mathrm{d}, J=7.1 \mathrm{~Hz}), 3.50$ $(2 \mathrm{H}+1 \mathrm{H}, \mathrm{d}, J=7.1 \mathrm{~Hz}), 3.39(3 \mathrm{H}, \mathrm{s}), 3.36(3 \mathrm{H}, \mathrm{s}), 2.61(1 \mathrm{H}, \mathrm{m}), 2.50(1 \mathrm{H}, \mathrm{qd}, J=7.4,1.9 \mathrm{~Hz})$; ${ }^{13} \mathrm{C}\left(75 \mathrm{MHz}, \mathrm{CDCl}_{3}\right) \delta 139.5,136.0,129.4,129.2,129.01,128.98,77.4,73.2,71.9,67.8,59.1$, 48.2, 41.8, 36.3, 21.3; HRMS calcd for $\mathrm{C}_{17} \mathrm{H}_{24} \mathrm{O}_{3}$ : 276.1725, found 276.1732.

Assay of enantiomeric excess: chiral HPLC (Chiracel OD, 5\% isopropanol/hexanes, 1 $\mathrm{mL} / \mathrm{min}, \lambda=254 \mathrm{~nm} ; \mathrm{t}_{\mathrm{r}}$ (major) $=5.7 \mathrm{~min} ., \mathrm{t}_{\mathrm{r}}($ minor $)=6.7 \mathrm{~min}$. $), 95 \%$ ee. $[\alpha]_{\mathrm{D}}{ }^{20}=+68(\mathrm{c}=$ $\left.1.31, \mathrm{CHCl}_{3}\right)$.

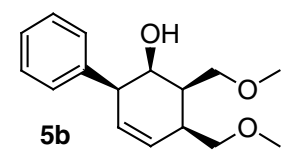

(+)-(1R, 2S, 5S, 6S)-5,6-Bis(methoxymethyl)-2-phenyl-cyclohex-3-enol

(5b): Purified by flash column chromatography ( 3/4" x 7" silica gel, eluted with 5-20 \% EtOAc/hexanes $)$. Yield $=91 \%$. Colourless oil. $\mathrm{R}_{\mathrm{f}}=0.10(20 \%$

EtOAc/hexanes); IR (film) $v=3389,2885,1490,1451,1390,1192,1162,1097,964,830,754$, $701 \mathrm{~cm}^{-1} ;{ }^{1} \mathrm{H}$ NMR $\left(300 \mathrm{MHz}, \mathrm{CDCl}_{3}\right) \delta$ 7.36-7.28 (2H, m), 7.28-7.18 (3H, m), 5.87 (1H, ddd, $J$ $=10.2,3.2,3.0 \mathrm{~Hz}), 5.81(1 \mathrm{H}, \mathrm{dm}, J=9.5 \mathrm{~Hz}), 3.91(1 \mathrm{H}, \mathrm{dm}, J=7.0 \mathrm{~Hz}), 3.73(1 \mathrm{H}, \mathrm{d}, J=9$ Hz), $3.58(2 \mathrm{H}, \mathrm{d}, J=7.5 \mathrm{~Hz}), 3.54(1 \mathrm{H}, \mathrm{m}) 3.51(2 \mathrm{H}, \mathrm{d}, J=3.6 \mathrm{~Hz}), 3.40(3 \mathrm{H}, \mathrm{s}), 3.37(3 \mathrm{H}, \mathrm{s})$, $2.64(1 \mathrm{H}, \mathrm{m}), 2.52(1 \mathrm{H}, \mathrm{qd}, J=7.5,2.1 \mathrm{~Hz}) ;{ }^{13} \mathrm{C}\left(100 \mathrm{MHz}, \mathrm{CDCl}_{3}\right) \delta 142.7,129.5,129.2$, 129.1, 128.3, 126.5, 73.2, 71.8, 67.8, 59.2, 59.1, 48.6, 41.8, 36.3; HRMS calcd for $\mathrm{C}_{16} \mathrm{H}_{22} \mathrm{O}_{3}$ : 262.1569, found 262.1562 .

Assay of enantiomeric excess: chiral HPLC (Chiracel OD, 2\% isopropanol/hexanes, 1 $\mathrm{mL} / \mathrm{min}, \lambda=254 \mathrm{~nm} ; \mathrm{t}_{\mathrm{r}}($ major $)=10.9 \min ., \mathrm{t}_{\mathrm{r}}($ minor $\left.)=8.5 \mathrm{~min}.\right), 95 \%$ ee. $[\alpha]_{\mathrm{D}}{ }^{20}=+76(\mathrm{c}=$ $\left.1.00, \mathrm{CHCl}_{3}\right)$.

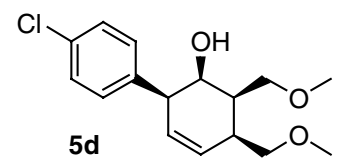

(+)-(1R, 2S, 5S, 6S)-5,6-Bis(methoxymethyl)-2-(4-chlorophenyl)-

cyclohex-3-enol (5d): Purified by flash column chromatography ( 3/4” x 7" silica gel, eluted with 5-20\% EtOAc/hexanes). Yield $=95 \%$. Colourless oil. $R_{f}=0.34$ (50\% EtOAc/hexanes); IR (film) $v=3383,2896,1489,1456,1091,1014,811$ $\mathrm{cm}^{-1} ;{ }^{1} \mathrm{H}$ NMR $\left(300 \mathrm{MHz}, \mathrm{CDCl}_{3}\right) \delta 7.27(2 \mathrm{H}, \mathrm{dm}, J=8.4 \mathrm{~Hz}), 7.16(2 \mathrm{H}, \mathrm{dm}, J=8.4 \mathrm{~Hz}), 5.87$ 
$(1 \mathrm{H}, \mathrm{ddd}, J=10.2,3.6,3.5 \mathrm{~Hz}), 5.73(1 \mathrm{H}, \mathrm{dd}, J=10.2,1.8 \mathrm{~Hz}), 4.0(1 \mathrm{H}, \mathrm{d}, J=9.9 \mathrm{~Hz}), 3.84$

$(1 \mathrm{H}, \mathrm{dm}, J=10.8 \mathrm{~Hz}) 3.55(2 \mathrm{H}, \mathrm{d}, J=9.0 \mathrm{~Hz}), 3.48(2 \mathrm{H}+1 \mathrm{H}, \mathrm{d}, J=3.0 \mathrm{~Hz}), 3.39(3 \mathrm{H}, \mathrm{s}), 3.36$

$(3 \mathrm{H}, \mathrm{s}), 2.62(1 \mathrm{H}, \mathrm{m}), 2.52(1 \mathrm{H}, \mathrm{qd}, J=7.4,1.8 \mathrm{~Hz}) ;{ }^{13} \mathrm{C}\left(75 \mathrm{MHz}, \mathrm{CDCl}_{3}\right) \delta 141.3,132.2$, 130.6 129.8, 128.8, 128.3, 73.2, 71.8, 67.8, 59.2, 59.1, 48.6, 41.8, 36.3; HRMS calcd for $\mathrm{C}_{16} \mathrm{H}_{21} \mathrm{O}_{3} \mathrm{Cl}: 296.1179$, found 296.1181.

Assay of enantiomeric excess: chiral HPLC (Chiracel OD, 5\% isopropanol/hexanes, 1 $\mathrm{mL} / \mathrm{min}, \lambda=220 \mathrm{~nm} ; \mathrm{t}_{\mathrm{r}}$ (major) $=6.2 \mathrm{~min} ., \mathrm{t}_{\mathrm{r}}($ minor $\left.)=7.5 \mathrm{~min}.\right), 95 \%$ ee. $[\alpha]_{\mathrm{D}}{ }^{20}=+59(\mathrm{c}=$ $\left.1.00, \mathrm{CHCl}_{3}\right)$.

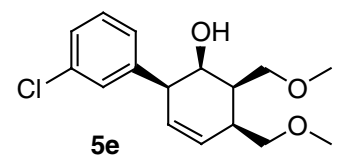

(+)-(1R, 2S, 5S, 6S)-5,6-Bis(methoxymethyl)-2-(3-chlorophenyl)cyclohex-3-enol (5e): Purified by flash column chromatography ( 3/4" x 7" silica gel, eluted with 5-20\% EtOAc/hexanes). Yield $=73 \%$. Colourless oil. $\mathrm{R}_{\mathrm{f}}=0.34(50 \%$ EtOAc/hexanes $)$; IR (film) v = 3374, 2895, 1597, 1477, 1459, 1199, 1168, 1097, 999, 899, 833, 781, $701 \mathrm{~cm}^{-1}$; ${ }^{1} \mathrm{H}$ NMR $\left(300 \mathrm{MHz}, \mathrm{CDCl}_{3}\right) \delta$ 7.25-7.16 (3H, m), 7.15-7.08 (1H, m), $5.87(1 \mathrm{H}, \mathrm{ddd}, J=9.9$, 3.5, 3.3 Hz), $5.73(1 \mathrm{H}, \mathrm{dm}, J=10.3 \mathrm{~Hz}), 4.0(1 \mathrm{H}, \mathrm{d}, J=9.6 \mathrm{~Hz}), 3.87(1 \mathrm{H}, \mathrm{dm}, J=9.6 \mathrm{~Hz}) 3.56$ $(2 \mathrm{H}, \mathrm{d}, J=7.5 \mathrm{~Hz}), 3.49(2 \mathrm{H}+1 \mathrm{H}, \mathrm{d}, J=3.3 \mathrm{~Hz}), 3.40(3 \mathrm{H}, \mathrm{s}), 3.37(3 \mathrm{H}, \mathrm{s}), 2.63(1 \mathrm{H}, \mathrm{m}), 2.52$ $(1 \mathrm{H}, \mathrm{qd}, J=7.5,2.1 \mathrm{~Hz}) ;{ }^{13} \mathrm{C}\left(75 \mathrm{MHz}, \mathrm{CDCl}_{3}\right) \delta 144.8,134.0,129.9,129.4,128.5,127.4$, 126.7, 73.0, 71.5, 67.4, 59.20, 59.15, 48.4, 41.7, 36.2; HRMS calcd for $\mathrm{C}_{16} \mathrm{H}_{20} \mathrm{O}_{3} \mathrm{Cl}$ : 295.1101, found 295.1097.

Assay of enantiomeric excess: chiral HPLC (Chiracel OD, 5\% isopropanol/hexanes, 1 $\mathrm{mL} / \mathrm{min}, \lambda=220 \mathrm{~nm} ; \mathrm{t}_{\mathrm{r}}$ (major) $=6.7 \mathrm{~min} ., \mathrm{t}_{\mathrm{r}}($ minor $)=3.2 \mathrm{~min}$. $), 99 \%$ ee. $[\alpha]_{\mathrm{D}}{ }^{20}=+59(\mathrm{c}=$ $\left.1.02, \mathrm{CHCl}_{3}\right)$.

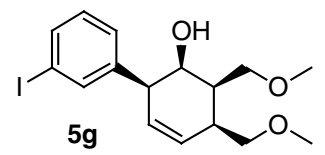

(+)-(1R, 2S, 5S, 6S)-5,6-Bis(methoxymethyl)-2-(3-iodophenyl)-cyclohex3-enol (5g): Purified by flash column chromatography ( 3/4" x 7" silica gel, eluted with 5-20\% EtOAc/hexanes). Yield $=85 \%$. Colourless oil. $\mathrm{R}_{\mathrm{f}}=$ 0.43 (50\% EtOAc/hexanes); IR (film) v = 3385, 2891, 1589, 1560, 1472, 1421, 1097, 1074, 990, 831, $776 \mathrm{~cm}^{-1} ;{ }^{1} \mathrm{H}$ NMR (300 MHz, $\left.\mathrm{CDCl}_{3}\right) \delta$ 7.64-7.51 (2H, m), $7.20(1 \mathrm{H}, \mathrm{d}, J=7.5 \mathrm{~Hz})$, 7.04(1H, d, $J=8.1 \mathrm{~Hz}) 5.85(1 \mathrm{H}, \mathrm{ddd}, J=10.2,3.3,3.3 \mathrm{~Hz}), 5.73(1 \mathrm{H}, \mathrm{dm}, J=9.9 \mathrm{~Hz}), 3.97$ 
$(1 \mathrm{H}, \mathrm{d}, J=9.9 \mathrm{~Hz}), 3.87(1 \mathrm{H}, \mathrm{dm}, J=9.6 \mathrm{~Hz}) 3.56(2 \mathrm{H}, \mathrm{d}, J=7.5 \mathrm{~Hz}), 3.49(2 \mathrm{H}, \mathrm{d}, J=3.0 \mathrm{~Hz})$, $3.45(1 \mathrm{H}, \mathrm{m}), 3.40(3 \mathrm{H}, \mathrm{s}), 3.37(3 \mathrm{H}, \mathrm{s}), 2.62(1 \mathrm{H}, \mathrm{m}), 2.52(1 \mathrm{H}, \mathrm{qd}, J=7.5,1.8 \mathrm{~Hz}) ;{ }^{13} \mathrm{C}(75$ $\left.\mathrm{MHz}, \mathrm{CDCl}_{3}\right) \delta 145.3,138.2,135.5,129.94,129.91,128.6,128.5,94.5,73.0,71.5,67.4,59.21$, 59.16, 48.3, 41.7, 36.2; HRMS calcd for $\mathrm{C}_{16} \mathrm{H}_{21} \mathrm{IO}_{3}$ : 388.0535, found 388.0536.

Assay of enantiomeric excess: chiral HPLC (Chiracel AD, 2\% isopropanol/hexanes, 1 $\mathrm{mL} / \mathrm{min}, \lambda=220 \mathrm{~nm} ; \mathrm{t}_{\mathrm{r}}($ major $)=10.7 \min ., \mathrm{t}_{\mathrm{r}}($ minor $\left.)=15.0 \mathrm{~min}.\right), 95 \%$ ee. $[\alpha]_{\mathrm{D}}{ }^{20}=+49(\mathrm{c}=$ $\left.1.00, \mathrm{CHCl}_{3}\right)$.

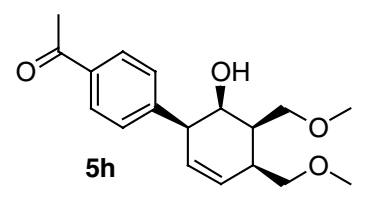

\section{(+)-(1R, 2S, 5S, 6S)-5,6-Bis(methoxymethyl)-2-(4-acetylphenyl)-} cyclohex-3-enol (5g): Purified by flash column chromatography ( 3/4” x 7" silica gel, eluted with 10-40\% EtOAc/hexanes). Yield $=85 \%$.

Colourless oil. $\mathrm{R}_{\mathrm{f}}=0.31$ (50\% EtOAc/hexanes); IR (film) $v=3382,2895,1670,1607,1359$, 1271, 1096, 959, $813 \mathrm{~cm}^{-1} ;{ }^{1} \mathrm{H}$ NMR $\left(300 \mathrm{MHz} \mathrm{CDCl}_{3}\right) \delta 7.91(2 \mathrm{H}, \mathrm{d}, J=8.1 \mathrm{~Hz}), 7.33(2 \mathrm{H}, \mathrm{d}$, $J=8.4 \mathrm{~Hz}), 5.88(1 \mathrm{H}, \mathrm{ddd}, J=10.2,3.3,3.3 \mathrm{~Hz}), 5.78(1 \mathrm{H}, \mathrm{dd}, J=10.2,1.8 \mathrm{~Hz}), 4.14(1 \mathrm{H}, \mathrm{d}, J$ $=9.9 \mathrm{~Hz}), 3.90(1 \mathrm{H}, \mathrm{dm}, J=9.9 \mathrm{~Hz}) 3.56(2 \mathrm{H}+1 \mathrm{H}, \mathrm{d}, J=7.5 \mathrm{~Hz}), 3.50(2 \mathrm{H}, \mathrm{d}, J=3.0 \mathrm{~Hz})$, $3.40(3 \mathrm{H}, \mathrm{s}), 3.37(3 \mathrm{H}, \mathrm{s}), 2.64(1 \mathrm{H}, \mathrm{m}), 2.60-2.49(3 \mathrm{H}+1 \mathrm{H}, \mathrm{m}) ;{ }^{13} \mathrm{C}\left(75 \mathrm{MHz}, \mathrm{CDCl}_{3}\right) \delta 198.0$, 148.4, 135.3, 129.7, 129.2, 128.2, 128.1, 72.7, 71.1, 67.1, 58.93, 58.90, 48.4, 41.5, 36.0, 26.6; HRMS calcd for $\mathrm{C}_{18} \mathrm{H}_{24} \mathrm{O}_{4}: 304.1675$, found 304.1669.

Assay of enantiomeric excess: chiral HPLC (Chiracel OD, 10\% isopropanol/hexanes, 1 $\mathrm{mL} / \mathrm{min}, \lambda=220 \mathrm{~nm} ; \mathrm{t}_{\mathrm{r}}$ (major) $=11.1 \mathrm{~min} ., \mathrm{t}_{\mathrm{r}}($ minor $\left.)=14.4 \mathrm{~min}.\right), 94 \%$ ee. $[\alpha]_{\mathrm{D}}{ }^{20}=+47(\mathrm{c}=$ $\left.1.03, \mathrm{CHCl}_{3}\right)$.

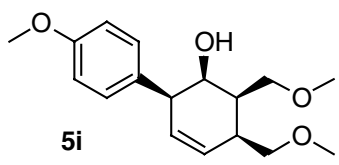

(+)-(1R, 2S, 5S, 6S)-5,6-Bis(methoxymethyl)-2-(4-methoxyphenyl)cyclohex-3-enol (5i): Purified by flash column chromatography $(\sim 3 / 4 " x$ 7" silica gel, eluted with 5-20\% EtOAc/hexanes). Yield $=87 \%$.

Colourless oil. $\mathrm{R}_{\mathrm{f}}=0.34$ (50\% EtOAc/hexanes);

IR (film) v = 3399, 2892, 1610, 1512, 1458, 1245, 1176, 1097, 1030, 815, $798 \mathrm{~cm}^{-1}$;

${ }^{1} \mathrm{H} \mathrm{NMR}\left(300 \mathrm{MHz}, \mathrm{CDCl}_{3}\right) \delta 7.15(2 \mathrm{H}, \mathrm{dm}, J=8.6 \mathrm{~Hz}), 6.86(2 \mathrm{H}, \mathrm{dm}, J=8.6 \mathrm{~Hz}), 5.85(1 \mathrm{H}$, $\mathrm{ddd}, J=10.3,3.4,3.4 \mathrm{~Hz}), 5.76(1 \mathrm{H}, \mathrm{dm}, J=10.2 \mathrm{~Hz}), 3.86(1 \mathrm{H}, \mathrm{dm}, J=9.9 \mathrm{~Hz}), 3.78(3 \mathrm{H}, \mathrm{s})$, $3.70(1 \mathrm{H}, \mathrm{d}, J=9.0 \mathrm{~Hz}), 3.56(2 \mathrm{H}, \mathrm{d}, J=7.4 \mathrm{~Hz}), 3.49(2 \mathrm{H}+1 \mathrm{H}, \mathrm{d}, J=3.4 \mathrm{~Hz}), 3.39(3 \mathrm{H}, \mathrm{s})$, 
$3.36(3 \mathrm{H}, \mathrm{s}), 2.61(1 \mathrm{H}, \mathrm{m}), 2.50(1 \mathrm{H}, \mathrm{qd}, J=7.5,2.1 \mathrm{~Hz}) ;{ }^{13} \mathrm{C}\left(75 \mathrm{MHz}, \mathrm{CDCl}_{3}\right) \delta 158.1,134.5$, 129.8, 129.14, 129.10, 113.5, 72.9, 71.6, 67.6, 58.9, 55.2, 47.5, 41.5, 36.0; HRMS calcd for $\mathrm{C}_{17} \mathrm{H}_{24} \mathrm{O}_{4}:$ 292.1675, found 292.1677.

Assay of enantiomeric excess: chiral HPLC (Chiracel OD, 10\% isopropanol/hexanes, 1 $\mathrm{mL} / \mathrm{min}, \lambda=220 \mathrm{~nm} ; \mathrm{t}_{\mathrm{r}}$ (major) $=6.6 \mathrm{~min} ., \mathrm{t}_{\mathrm{r}}($ minor $\left.)=9.5 \mathrm{~min}.\right), 96 \%$ ee. $[\alpha]_{\mathrm{D}}{ }^{20}=+50(\mathrm{c}=$ $\left.1.14, \mathrm{CHCl}_{3}\right)$.

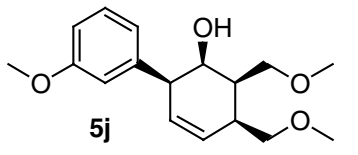

(+)-(1R, 2S, 5S, 6S)-5,6-Bis(methoxymethyl)-2-(3-methoxyphenyl)cyclohex-3-enol (5j): Purified by flash column chromatography $(\sim 3 / 4 " x$ 7" silica gel, eluted with 5-20 \% EtOAc/hexanes). Yield $=91 \%$.

Colourless oil. $\mathrm{R}_{\mathrm{f}}=0.34$ (50\% EtOAc/hexanes);

IR (film) $v=3379,2886,2837,1599,1585,1487,1459,1286,1265,1198,1167,1093,1054$, 998, 777, $699 \mathrm{~cm}^{-1} ;{ }^{1} \mathrm{H}$ NMR (400 MHz, $\left.\mathrm{CDCl}_{3}\right) \delta 7.23(1 \mathrm{H}, \mathrm{t}, J=7.9 \mathrm{~Hz}), 6.86-6.70(3 \mathrm{H}, \mathrm{m})$, $5.85(1 \mathrm{H}, \mathrm{dm}, J=10.3), 5.79(1 \mathrm{H}, \mathrm{dm}, J=10.3 \mathrm{~Hz}), 3.91(1 \mathrm{H}, \mathrm{dm}, J=8.0 \mathrm{~Hz}), 3.78(3 \mathrm{H}, \mathrm{s})$, $3.66(1 \mathrm{H}, \mathrm{d}, J=9.2 \mathrm{~Hz}), 3.56(2 \mathrm{H}, \mathrm{d}, J=7.5 \mathrm{~Hz}), 3.52-3.42(2 \mathrm{H}+1 \mathrm{H}, \mathrm{d}, J=3.5 \mathrm{~Hz}), 3.39(3 \mathrm{H}$, s), $3.37(3 \mathrm{H}, \mathrm{s}), 2.61(1 \mathrm{H}, \mathrm{m}), 2.50(1 \mathrm{H}, \mathrm{qd}, J=7.5,2.1 \mathrm{~Hz}) ;{ }^{13} \mathrm{C}\left(100 \mathrm{MHz}, \mathrm{CDCl}_{3}\right) \delta 159.6$, 144.2, 129.5, 129.1, 128.8, 121.5, 114.9, 111.8, 76.9, 73.1, 71.8, 67.7, 59.1, 55.3, 48.5, 41.7, 36.2; HRMS calcd for $\mathrm{C}_{17} \mathrm{H}_{24} \mathrm{O}_{4}$ : 292.1675, found 292.1674.

Assay of enantiomeric excess: chiral HPLC (Chiracel OD, 5\% isopropanol/hexanes, 1 $\mathrm{mL} / \mathrm{min}, \lambda=254 \mathrm{~nm} ; \mathrm{t}_{\mathrm{r}}$ (major) $=9.2 \min ., \mathrm{t}_{\mathrm{r}}($ minor $)=15.7 \mathrm{~min}$. $), 95 \%$ ee. $[\alpha]_{\mathrm{D}}{ }^{20}=+70(\mathrm{c}=$ $\left.1.00, \mathrm{CHCl}_{3}\right)$.

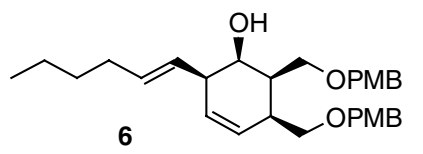

(+)-(1R, 2R, 5S, 6S)-5,6-Bis(p-methoxybenzyloxymethyl)-2-(1-(E)-

hexenyl)-cyclohex-3-enol (6): Purified by flash column chromatography ( 1/2" x 7" silica gel, eluted with 5-10\%

EtOAc/hexanes). Yield $=95 \%$. Colourless oil. $R_{\mathrm{f}}=0.27$ (20\% EtOAc/hexanes); IR (film) $v=$ $3406,2924,2855,1611,1585,1512,1467,1364,1299,1246,1170,1070,1032,971,819,758$ $\mathrm{cm}^{-1} ;{ }^{1} \mathrm{H}$ NMR $\left(300 \mathrm{MHz}, \mathrm{CDCl}_{3}\right) \delta 7.22(4 \mathrm{H}, \mathrm{tm}, J=8.7 \mathrm{~Hz}), 6.91-6.83(4 \mathrm{H}, \mathrm{m}), 5.69-5.45$ $(4 \mathrm{H}, \mathrm{m}), 4.48(1 \mathrm{H}, \mathrm{d}, J=12.0 \mathrm{~Hz}), 4.34(2 \mathrm{H}, \mathrm{d}, J=11.7 \mathrm{~Hz}), 4.23(1 \mathrm{H}, \mathrm{d}, J=11.4 \mathrm{~Hz}), 3.87$ $(1 \mathrm{H}, \mathrm{d}, J=9.6 \mathrm{~Hz}), 3.80(6 \mathrm{H}, \mathrm{s}), 3.77(1 \mathrm{H}, \mathrm{m}), 3.58-3.36(4 \mathrm{H}, \mathrm{m}), 2.80(1 \mathrm{H}, \mathrm{m}), 2.55(1 \mathrm{H}, \mathrm{m})$, 
$2.35(1 \mathrm{H}, \mathrm{qm}, J=7.8 \mathrm{~Hz}), 2.05(2 \mathrm{H}, \mathrm{q}, J=6.9 \mathrm{~Hz}), 1.42-1.20(4 \mathrm{H}, \mathrm{m}), 0.89(3 \mathrm{H}, \mathrm{t}, \mathrm{J}=7.2 \mathrm{~Hz})$; ${ }^{13} \mathrm{C}\left(75 \mathrm{MHz}, \mathrm{CDCl}_{3}\right) \delta 159.6,159.4,132.1,131.0,130.7,130.1,129.7,129.6,129.5,128.3$, 114.04, 113.98, 76.8, 73.11, 73.08, 70.5, 68.4, 67.9, 55.5, 45.8, 41.6, 36.2, 32.6, 31.9, 22.5, 14.2; HRMS calcd for $\mathrm{C}_{30} \mathrm{H}_{40} \mathrm{O}_{5}: 480.2876$, found 480.2864 .

Assay of enantiomeric excess: chiral HPLC (Chiracel AD, 5\% isopropanol/hexanes, 1 $\mathrm{mL} / \mathrm{min}, \lambda=254 \mathrm{~nm} ; \mathrm{t}_{\mathrm{r}}$ (major) $=13.2 \mathrm{~min}$., $\mathrm{t}_{\mathrm{r}}($ minor $)=10.7 \mathrm{~min}$. $), 92 \%$ ee. $[\alpha]_{\mathrm{D}}{ }^{20}=+26(\mathrm{c}=$ $\left.1.14, \mathrm{CHCl}_{3}\right)$.

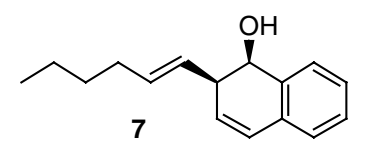

(-)-(1R, 2R)-1,2-Dihydro-2-(1-(E)-hexenyl)-1-naphthol (7): Purified by flash column chromatography ( 1/2" x 3" silica gel, eluted with $4 \%$ EtOAc/hexanes). Yield $=93 \%$. Colourless oil. $R_{\mathrm{f}}=0.45(25 \%$ EtOAc/hexanes); IR (film) $v=3423,3032,2956,2926,2856,1483,1452,1378,1187,1050$, 971, 786, 764, 695, $660 \mathrm{~cm}^{-1} ;{ }^{1} \mathrm{H}$ NMR $\left(300 \mathrm{MHz}, \mathrm{CDCl}_{3}\right) \delta$ 7.50-7.39 $(1 \mathrm{H}, \mathrm{m}), 7.32-7.18(2 \mathrm{H}$, m), 7.12-7.02 (1H, m), $6.49(1 \mathrm{H}, \mathrm{dd}, J=9.6,1.2 \mathrm{~Hz}), 5.94(1 \mathrm{H}, \mathrm{dd}, J=9.5,4.8 \mathrm{~Hz}), 5.73(1 \mathrm{H}$, $\mathrm{dt}, J=15.6,6.6 \mathrm{~Hz}), 5.34(1 \mathrm{H}, \mathrm{dd}, J=15.3,8.7 \mathrm{~Hz}), 4.80(1 \mathrm{H}, \mathrm{dd}, J=8.6,5.7 \mathrm{~Hz}), 3.13(1 \mathrm{H}$, m), $2.05(2 \mathrm{H}, \mathrm{dt}, J=6.9,6.9 \mathrm{~Hz}), 1.80(1 \mathrm{H}, \mathrm{d}, J=8.4 \mathrm{~Hz}) 1.42-1.20(4 \mathrm{H}, \mathrm{m}), 0.89(3 \mathrm{H}, \mathrm{t}, \mathrm{J}=$ $7.2 \mathrm{~Hz}) ;{ }^{13} \mathrm{C}\left(100 \mathrm{MHz}, \mathrm{CDCl}_{3}\right) \delta 137.4,136.6,132.9,130.0,128.1,128.0,127.4,126.5,126.2$, 125.8; HRMS calcd for $\mathrm{C}_{16} \mathrm{H}_{20} \mathrm{O}: 228.1514$, found 228.1513 .

Assay of enantiomeric excess: chiral HPLC (Chiracel OD, 2\% isopropanol/hexanes, 1 $\mathrm{mL} / \mathrm{min}, \lambda=254 \mathrm{~nm} ; \mathrm{t}_{\mathrm{r}}$ (major) $=7.8 \min ., \mathrm{t}_{\mathrm{r}}($ minor $)=9.5 \mathrm{~min}$. $), 88 \%$ ee. $[\alpha]_{\mathrm{D}}^{20}=-259(\mathrm{c}=$ $\left.0.64, \mathrm{CHCl}_{3}\right)$.

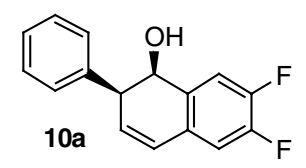

(-)-(1R, 2S)-6,7-Difluoro-1,2-dihydro-2-phenyl-1-naphthol (10a): Note: Compound is light-sensitive, especially in non-polar solvents like hexane and dichloromethane. Purified by flash column chromatography ( 1/2" x 7" silica gel, eluted with 2-10\% EtOAc/hexanes. Crude material was adsorbed onto a minimum of silica gel and transferred onto column). Yield $=60 \%$. Pale yellow oil. $\mathrm{R}_{\mathrm{f}}=0.27(25 \%$ EtOAc/hexanes); IR (film) $v=3379,3401,1594,1508,1377,1308,1108,1067,881,777$, $760,702 \mathrm{~cm}^{-1} ;{ }^{1} \mathrm{H}$ NMR $\left(300 \mathrm{MHz}, \mathrm{CD}_{3} \mathrm{OD}\right) \delta$ 7.27-7.13 (6H, m), $7.09(1 \mathrm{H}, \mathrm{dd}, J=11.1,7.8$ Hz), $6.63(1 \mathrm{H}, \mathrm{dd}, J=9.6,1.8 \mathrm{~Hz}), 6.15(1 \mathrm{H}, \mathrm{dd}, J=9.6,4.5 \mathrm{~Hz}), 4.89(1 \mathrm{H}, \mathrm{d}, J=6.3 \mathrm{~Hz})$, 
$3.76(1 \mathrm{H}, \mathrm{m}) ;{ }^{13} \mathrm{C}\left(75.5 \mathrm{MHz}, \mathrm{CD}_{3} \mathrm{OD}\right) \delta 151.1\left(\mathrm{dd}, J^{C-F}=245,12.9 \mathrm{~Hz}\right), 150.9\left(\mathrm{dd}, J^{C-F}=\right.$ 247, $12.6 \mathrm{~Hz}), 139.4,135.7$ (m), 132.71, 132.68, 131.8 (m), 130.7, 129.3, 128.1, 127.3, 116.8 $\left(\mathrm{d}, J^{C-F}=18.6 \mathrm{~Hz}\right), 115.9\left(\mathrm{~d}, J^{C-F}=18.0 \mathrm{~Hz}\right), 71.4,48.2 ;{ }^{19} \mathrm{~F} \mathrm{NMR}\left(282.3 \mathrm{MHz}, \mathrm{CD}_{3} \mathrm{OD}\right) \delta-$ 133.9 (ddd, $J=20.6,10.7,8.5 \mathrm{~Hz}$ ), -140.1 (ddd, $J=20.0,10.4,8.2 \mathrm{~Hz}$ ); HRMS calcd for $\mathrm{C}_{16} \mathrm{H}_{12} \mathrm{~F}_{2} \mathrm{O}: 258.0856$, found 258.0857.

Assay of enantiomeric excess: chiral HPLC (Chiracel OD, 5\% isopropanol/hexanes, 1 $\mathrm{mL} / \mathrm{min}, \lambda=254 \mathrm{~nm} ; \mathrm{t}_{\mathrm{r}}($ major $)=10.5 \mathrm{~min} ., \mathrm{t}_{\mathrm{r}}($ minor $)=18.8 \mathrm{~min}$.), $91 \%$ ee. $[\alpha]_{\mathrm{D}}{ }^{20}=-163(\mathrm{c}=$ $0.64, \mathrm{MeOH})$. 


\section{X-ray data for compound 14:}

Figure 1. X-ray crystal structure of $\mathbf{1 4}$ (conformer A).

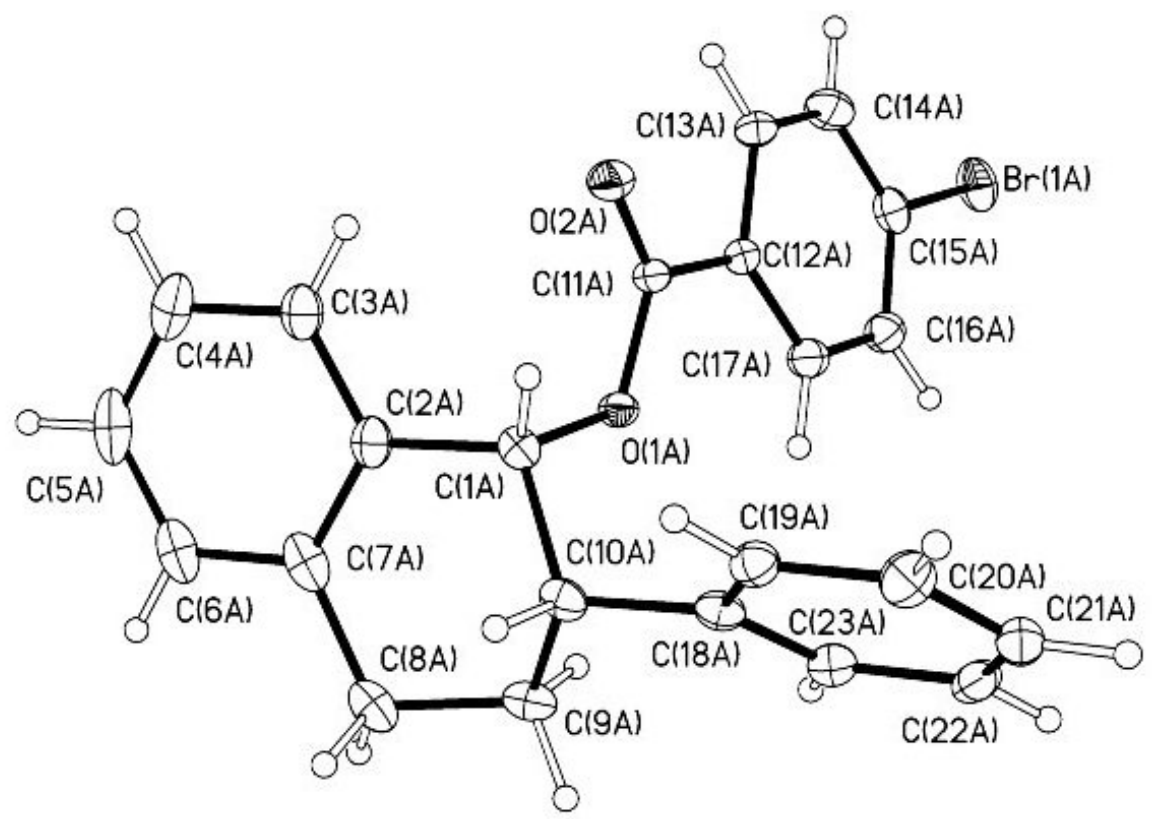


Figure 2. X-ray crystal structure of $\mathbf{1 4}$ (conformer B).

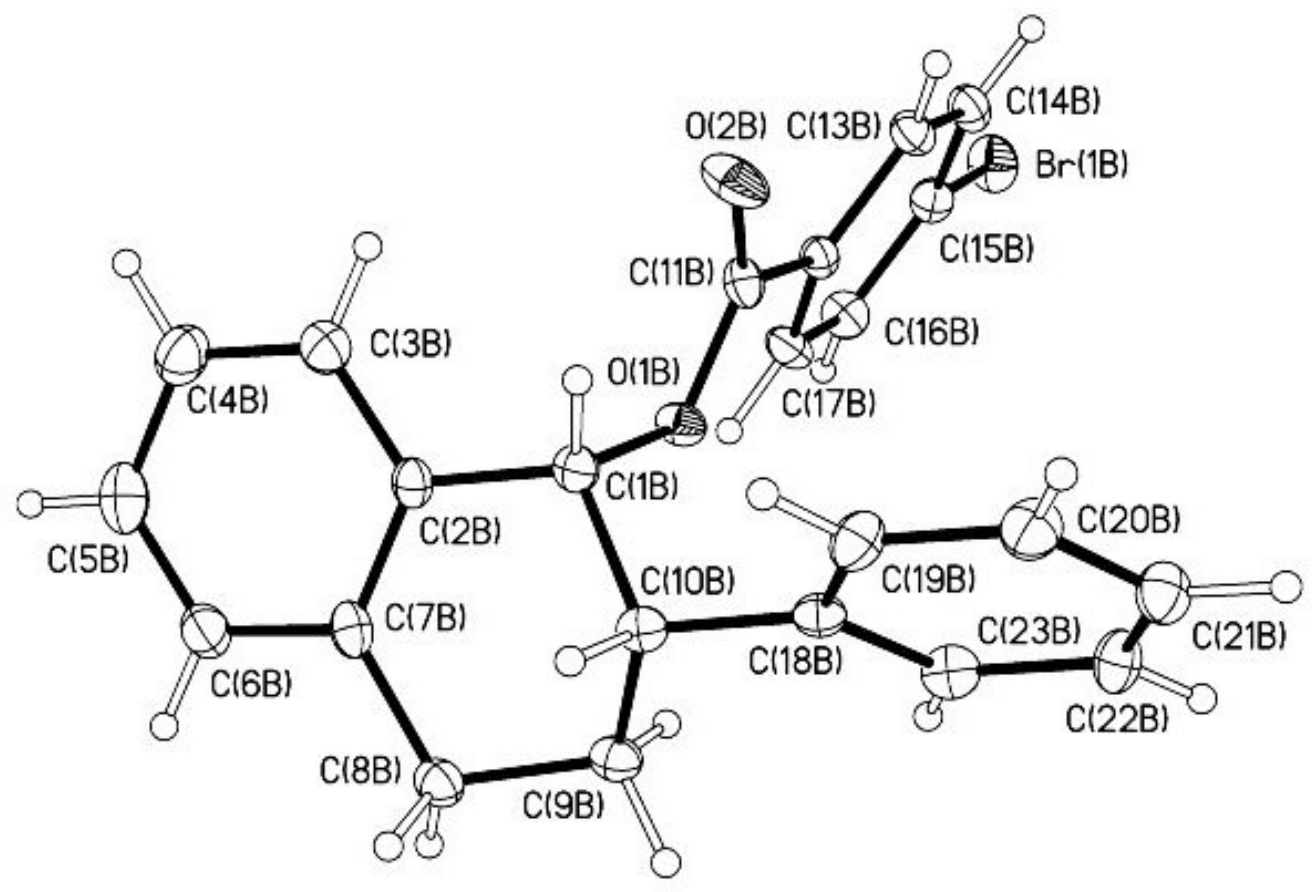


Figure 3. X-ray crystal structure of $\mathbf{1 4}$ (conformer C)

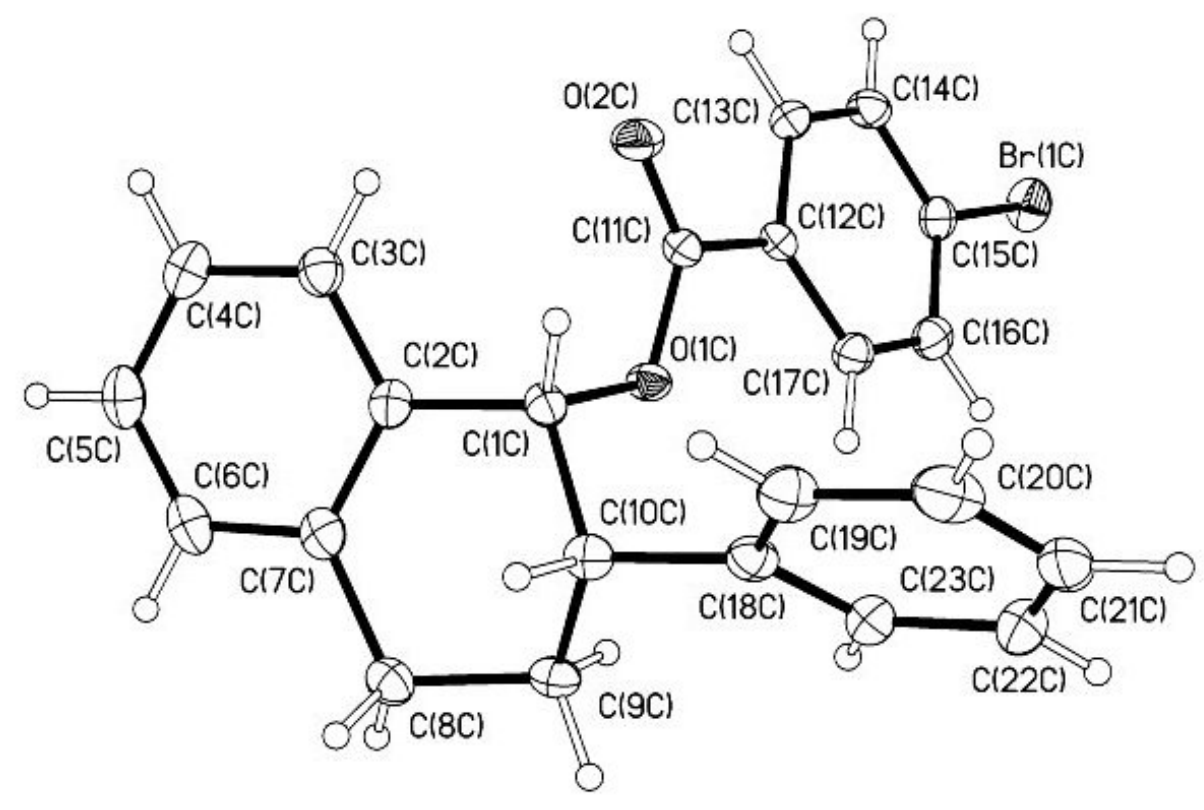


Figure 4. X-ray crystal structure of $\mathbf{1 4}$ (conformer D).

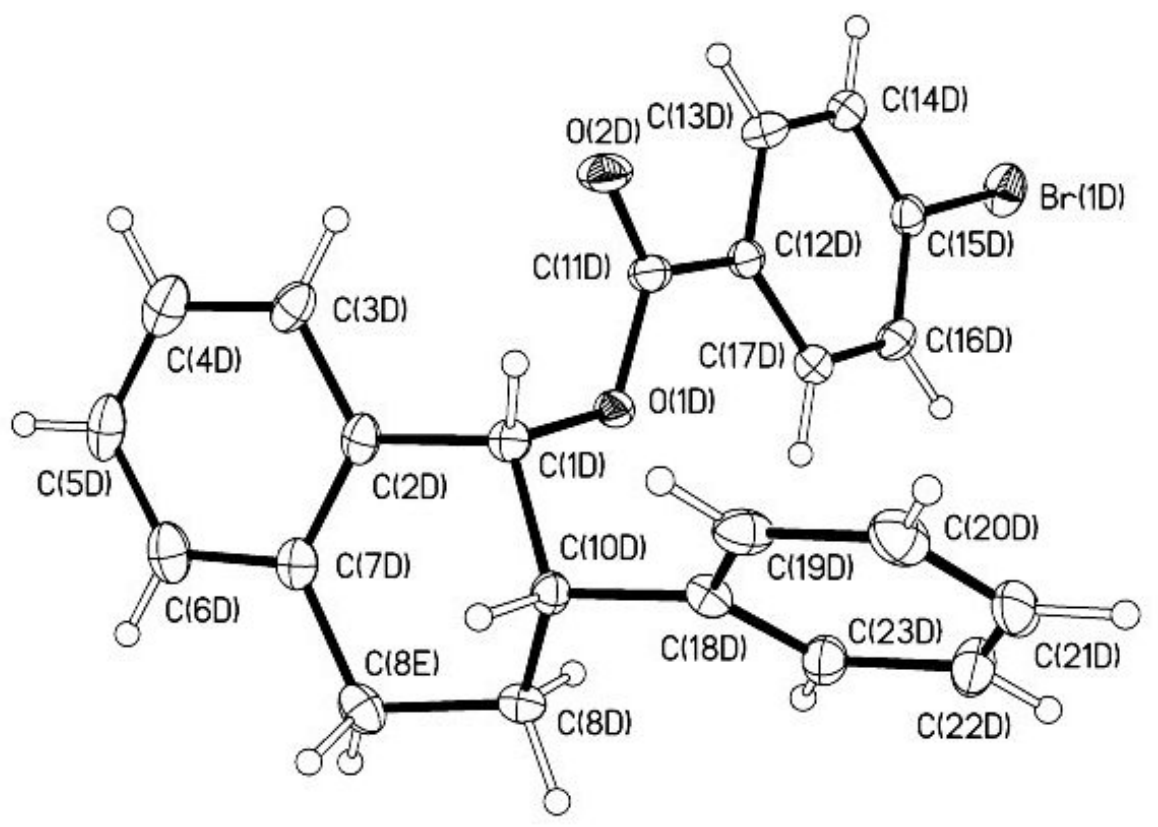


Table 2. Crystal data and structure refinement for $\mathbf{1 4}$.

Identification code

Empirical formula

Formula weight

Temperature

Wavelength

Crystal system

Space group

Unit cell dimensions

Volume

Z

Density (calculated)

Absorption coefficient

$\mathrm{F}(000)$

Crystal size

Theta range for data collection

Index ranges

Reflections collected

Independent reflections

Completeness to theta $=27.42^{\circ}$

Absorption correction

Max. and min. transmission

Refinement method

Data / restraints / parameters

Goodness-of-fit on $\mathrm{F}^{2}$

Final $\mathrm{R}$ indices [I $>2 \operatorname{sigma}(\mathrm{I})]$

$\mathrm{R}$ indices (all data)

Absolute structure parameter

Extinction coefficient

Largest diff. peak and hole k0204

C23 H19 Br O2

407.29

150(1) K

$0.71073 \AA$

Triclinic

P1

$\mathrm{a}=6.05380(10) \AA \quad \alpha=116.3490(10)^{\circ}$.

$\mathrm{b}=17.6308(2) \AA \quad \beta=92.5730(10)^{\circ}$.

$\mathrm{c}=19.3609(3) \AA \quad \gamma=93.8090(10)^{\circ}$.

1841.27(5) $\AA^{3}$

4

$1.469 \mathrm{Mg} / \mathrm{m}^{3}$

$2.247 \mathrm{~mm}^{-1}$

832

$0.30 \times 0.10 \times 0.10 \mathrm{~mm}^{3}$

2.59 to $27.42^{\circ}$.

$-7<=\mathrm{h}<=7,-22<=\mathrm{k}<=22,-24<=\mathrm{l}<=24$

24177

$15135[\mathrm{R}(\mathrm{int})=0.074]$

$99.2 \%$

None

0.8065 and 0.5522

Full-matrix least-squares on $\mathrm{F}^{2}$

15135 / 3 / 938

0.992

$\mathrm{R} 1=0.0460, \mathrm{wR} 2=0.0868$

$\mathrm{R} 1=0.0760, \mathrm{wR} 2=0.0999$

$0.002(5)$

$0.0065(5)$

0.473 and -0.439 e. $\AA^{-3}$ 
Table 3. Atomic coordinates ( $\left.\mathrm{x} 10^{4}\right)$ and equivalent isotropic displacement parameters $\left(\AA^{2} \mathrm{x}\right.$ $10^{3}$ ) for $\mathbf{1 4}$. $\mathrm{U}(\mathrm{eq})$ is defined as one third of the trace of the orthogonalized $\mathrm{U}^{\mathrm{ij}}$ tensor.

\begin{tabular}{|c|c|c|c|c|}
\hline & $\mathrm{x}$ & $\mathrm{y}$ & $\mathrm{z}$ & $\mathrm{U}(\mathrm{eq})$ \\
\hline $\operatorname{Br}(1 \mathrm{~A})$ & 2804(1) & $3590(1)$ & 6896(1) & $45(1)$ \\
\hline $\mathrm{O}(1 \mathrm{~A})$ & $5535(4)$ & $5709(2)$ & $4807(2)$ & $24(1)$ \\
\hline $\mathrm{O}(2 \mathrm{~A})$ & $8924(5)$ & $5319(2)$ & 4957(2) & $35(1)$ \\
\hline $\mathrm{C}(1 \mathrm{~A})$ & $6397(7)$ & 6108(3) & $4334(2)$ & $26(1)$ \\
\hline $\mathrm{C}(2 \mathrm{~A})$ & $6092(8)$ & $5459(3)$ & 3492(3) & $31(1)$ \\
\hline $\mathrm{C}(3 \mathrm{~A})$ & $7665(8)$ & $4868(3)$ & 3191(3) & $35(1)$ \\
\hline $\mathrm{C}(4 \mathrm{~A})$ & $7422(10)$ & $4266(3)$ & $2418(3)$ & $49(1)$ \\
\hline$C(5 A)$ & $5613(10)$ & $4255(4)$ & 1948(3) & $53(2)$ \\
\hline$C(6 A)$ & $4077(9)$ & 4838(4) & $2240(3)$ & $44(1)$ \\
\hline $\mathrm{C}(7 \mathrm{~A})$ & $4309(8)$ & $5447(3)$ & 3012(3) & $36(1)$ \\
\hline $\mathrm{C}(8 \mathrm{~A})$ & $2626(8)$ & 6102(3) & $3298(3)$ & $36(1)$ \\
\hline $\mathrm{C}(9 \mathrm{~A})$ & $2699(7)$ & 6571(3) & 4173(3) & $33(1)$ \\
\hline$C(10 A)$ & $5119(7)$ & 6879(3) & 4512(3) & $28(1)$ \\
\hline$C(11 \mathrm{~A})$ & $6985(7)$ & $5336(3)$ & $5073(2)$ & $26(1)$ \\
\hline$C(12 A)$ & $5902(7)$ & 4938(3) & $5526(2)$ & $26(1)$ \\
\hline$C(13 A)$ & $7062(8)$ & 4364(3) & $5674(3)$ & $33(1)$ \\
\hline$C(14 A)$ & $6158(8)$ & 3964(3) & 6081(3) & $41(1)$ \\
\hline$C(15 A)$ & $4110(8)$ & $4162(3)$ & $6369(3)$ & $33(1)$ \\
\hline$C(16 A)$ & 2959(8) & $4749(3)$ & $6246(3)$ & $33(1)$ \\
\hline $\mathrm{C}(17 \mathrm{~A})$ & $3847(8)$ & $5122(3)$ & $5810(3)$ & $32(1)$ \\
\hline $\mathrm{C}(18 \mathrm{~A})$ & $5397(7)$ & 7533(3) & $5353(3)$ & $28(1)$ \\
\hline$C(19 A)$ & $7323(7)$ & $8074(3)$ & $5624(3)$ & $30(1)$ \\
\hline$C(20 A)$ & $7635(9)$ & $8720(3)$ & 6378(3) & $39(1)$ \\
\hline$C(21 \mathrm{~A})$ & $5979(9)$ & $8815(3)$ & 6876(3) & $38(1)$ \\
\hline$C(22 \mathrm{~A})$ & 4076(9) & $8265(3)$ & 6618(3) & $35(1)$ \\
\hline$C(23 \mathrm{~A})$ & $3766(7)$ & 7619(3) & $5865(3)$ & $31(1)$ \\
\hline $\operatorname{Br}(1 \mathrm{~B})$ & $8369(1)$ & $12142(1)$ & 7052(1) & $45(1)$ \\
\hline $\mathrm{O}(1 \mathrm{~B})$ & 10432(4) & $9832(2)$ & $8987(2)$ & $27(1)$ \\
\hline $\mathrm{O}(2 \mathrm{~B})$ & $13825(5)$ & $9851(2)$ & $8557(2)$ & $44(1)$ \\
\hline $\mathrm{C}(1 \mathrm{~B})$ & $11195(7)$ & $9462(3)$ & $9498(2)$ & $26(1)$ \\
\hline $\mathrm{C}(2 \mathrm{~B})$ & $11050(7)$ & 10121(3) & $10313(2)$ & $26(1)$ \\
\hline
\end{tabular}




\begin{tabular}{|c|c|c|c|c|}
\hline $\mathrm{C}(3 \mathrm{~B})$ & $12733(8)$ & $10778(3)$ & $10656(3)$ & $37(1)$ \\
\hline$C(4 B)$ & $12680(9)$ & $11407(3)$ & $11402(3)$ & $45(1)$ \\
\hline $\mathrm{C}(5 \mathrm{~B})$ & $10885(10)$ & $11377(4)$ & 11818(3) & $48(1)$ \\
\hline$C(6 B)$ & $9217(8)$ & $10723(3)$ & 11484(3) & $40(1)$ \\
\hline $\mathrm{C}(7 \mathrm{~B})$ & $9244(8)$ & $10082(3)$ & $10725(3)$ & $31(1)$ \\
\hline $\mathrm{C}(8 \mathrm{~B})$ & $7416(7)$ & $9364(3)$ & 10387(3) & $31(1)$ \\
\hline $\mathrm{C}(9 \mathrm{~B})$ & 7366(7) & $8861(3)$ & $9511(3)$ & $29(1)$ \\
\hline$C(10 B)$ & $9704(7)$ & $8644(3)$ & $9278(3)$ & $25(1)$ \\
\hline $\mathrm{C}(11 \mathrm{~B})$ & 11905(7) & 10018(3) & $8582(2)$ & $27(1)$ \\
\hline$C(12 B)$ & 10951(7) & 10483(3) & $8175(2)$ & $23(1)$ \\
\hline$C(13 B)$ & 12116(7) & $10582(3)$ & $7609(3)$ & $29(1)$ \\
\hline$C(14 B)$ & 11331(8) & $11055(3)$ & $7254(3)$ & $32(1)$ \\
\hline$C(15 B)$ & $9407(7)$ & 11437(3) & $7485(3)$ & $30(1)$ \\
\hline$C(16 B)$ & $8241(8)$ & 11354(3) & $8048(3)$ & $34(1)$ \\
\hline$C(17 B)$ & $9005(8)$ & 10863(3) & $8387(3)$ & $33(1)$ \\
\hline$C(18 B)$ & $9834(7)$ & 7997(3) & $8448(3)$ & $26(1)$ \\
\hline$C(19 B)$ & $11654(7)$ & $7522(3)$ & $8245(3)$ & $33(1)$ \\
\hline$C(20 B)$ & 11802(8) & $6899(3)$ & $7500(3)$ & $37(1)$ \\
\hline$C(21 B)$ & 10131(8) & $6743(3)$ & $6932(3)$ & $35(1)$ \\
\hline$C(22 B)$ & $8334(8)$ & $7215(3)$ & 7113(3) & $34(1)$ \\
\hline$C(23 B)$ & $8169(7)$ & 7838(3) & $7869(3)$ & $31(1)$ \\
\hline $\operatorname{Br}(1 \mathrm{C})$ & $14845(1)$ & $8516(1)$ & $3572(1)$ & $45(1)$ \\
\hline $\mathrm{O}(1 \mathrm{C})$ & $16758(5)$ & $4939(2)$ & $368(2)$ & $27(1)$ \\
\hline $\mathrm{O}(2 \mathrm{C})$ & $20276(5)$ & $5361(2)$ & $907(2)$ & $40(1)$ \\
\hline$C(1 C)$ & 17503(7) & 4187(3) & $-274(2)$ & $26(1)$ \\
\hline$C(2 C)$ & $17440(7)$ & $3456(3)$ & $-55(3)$ & $28(1)$ \\
\hline$C(3 C)$ & 19242(8) & $3391(3)$ & $381(3)$ & $33(1)$ \\
\hline$C(4 C)$ & 19225(9) & 2734(3) & $587(3)$ & $38(1)$ \\
\hline$C(5 C)$ & $17387(10)$ & 2138(3) & $361(3)$ & $43(1)$ \\
\hline$C(6 C)$ & $15620(9)$ & 2199(3) & $-76(3)$ & $40(1)$ \\
\hline$C(7 C)$ & $15612(7)$ & $2846(3)$ & $-303(3)$ & $32(1)$ \\
\hline$C(8 C)$ & 13683(8) & 2858(3) & $-816(3)$ & $34(1)$ \\
\hline$C(9 C)$ & $13596(7)$ & $3701(3)$ & $-860(3)$ & $31(1)$ \\
\hline$C(10 C)$ & $15924(7)$ & 4003(3) & $-979(2)$ & $29(1)$ \\
\hline $\mathrm{C}(11 \mathrm{C})$ & 18310(7) & $5463(3)$ & $911(3)$ & $26(1)$ \\
\hline$C(12 C)$ & $17405(7)$ & $6204(3)$ & $1534(2)$ & $26(1)$ \\
\hline
\end{tabular}




\begin{tabular}{|c|c|c|c|c|}
\hline$C(13 C)$ & $18723(8)$ & 6667(3) & $2207(3)$ & $32(1)$ \\
\hline$C(14 C)$ & $18017(8)$ & 7363(3) & $2820(3)$ & $33(1)$ \\
\hline$C(15 C)$ & $15903(7)$ & 7597(3) & $2729(3)$ & $30(1)$ \\
\hline$C(16 C)$ & $14548(8)$ & $7150(3)$ & $2049(3)$ & $33(1)$ \\
\hline $\mathrm{C}(17 \mathrm{C})$ & $15285(7)$ & 6451(3) & $1452(3)$ & $30(1)$ \\
\hline$C(18 C)$ & $16032(8)$ & 4732(3) & $-1197(3)$ & $31(1)$ \\
\hline$C(19 C)$ & $17760(8)$ & $4826(3)$ & $-1606(3)$ & $39(1)$ \\
\hline$C(20 C)$ & $17908(10)$ & $5467(4)$ & $-1832(3)$ & $49(1)$ \\
\hline$C(21 C)$ & $16283(10)$ & 6020(4) & $-1654(3)$ & $51(2)$ \\
\hline$C(22 C)$ & $14529(10)$ & 5939(3) & $-1244(3)$ & $48(1)$ \\
\hline$C(23 C)$ & $14437(9)$ & $5305(3)$ & $-1010(3)$ & $40(1)$ \\
\hline $\operatorname{Br}(1 \mathrm{D})$ & $9354(1)$ & 6994(1) & 136(1) & $45(1)$ \\
\hline $\mathrm{O}(1 \mathrm{D})$ & $12575(5)$ & $10627(2)$ & $3441(2)$ & $25(1)$ \\
\hline $\mathrm{O}(2 \mathrm{D})$ & $15926(5)$ & $10329(2)$ & $2968(2)$ & $39(1)$ \\
\hline C(1D) & $13600(7)$ & 11399(3) & $4098(2)$ & $26(1)$ \\
\hline$C(2 D)$ & $13520(7)$ & $12147(3)$ & $3903(2)$ & $29(1)$ \\
\hline$C(3 D)$ & $15180(8)$ & $12273(3)$ & $3467(3)$ & $34(1)$ \\
\hline$C(4 D)$ & $15123(10)$ & 12944(3) & $3280(3)$ & $46(1)$ \\
\hline$C(5 D)$ & $13458(10)$ & $13484(3)$ & $3514(3)$ & $45(1)$ \\
\hline$C(6 D)$ & 11869(9) & 13363(3) & $3951(3)$ & $41(1)$ \\
\hline C(7D) & $11864(7)$ & $12697(3)$ & $4158(3)$ & $31(1)$ \\
\hline$C(8 D)$ & $9973(7)$ & 11744(3) & $4669(3)$ & $28(1)$ \\
\hline$C(8 E)$ & $10168(8)$ & $12614(3)$ & $4674(3)$ & $34(1)$ \\
\hline$C(10 D)$ & $12290(7)$ & 11512(3) & $4789(2)$ & $24(1)$ \\
\hline$C(11 D)$ & $13930(7)$ & $10156(3)$ & 2917(3) & $28(1)$ \\
\hline$C(12 D)$ & 12733(7) & 9399(3) & $2272(2)$ & $25(1)$ \\
\hline$C(13 D)$ & $13872(7)$ & 8964(3) & $1622(3)$ & $33(1)$ \\
\hline$C(14 D)$ & $12910(8)$ & $8246(3)$ & $989(3)$ & $33(1)$ \\
\hline$C(15 D)$ & $10737(8)$ & 7956(3) & $1008(2)$ & $29(1)$ \\
\hline$C(16 D)$ & $9559(7)$ & $8367(3)$ & $1648(3)$ & $30(1)$ \\
\hline$C(17 D)$ & $10540(7)$ & 9096(3) & $2270(3)$ & $28(1)$ \\
\hline$C(18 D)$ & $12367(7)$ & $10759(3)$ & $4967(2)$ & $27(1)$ \\
\hline C(19D) & $14279(8)$ & 10664(3) & $5332(3)$ & $36(1)$ \\
\hline$C(20 D)$ & $14367(9)$ & $10000(3)$ & $5529(3)$ & $42(1)$ \\
\hline$C(21 D)$ & $12546(10)$ & $9416(3)$ & $5357(3)$ & $47(1)$ \\
\hline C(22D) & $10650(10)$ & 9489(3) & 4982(3) & $47(1)$ \\
\hline
\end{tabular}


Table 4. Bond lengths $[\AA]$ and angles $\left[{ }^{\circ}\right]$ for 14 .

\begin{tabular}{|c|c|}
\hline $\mathrm{Br}(1 \mathrm{~A})-\mathrm{C}(15 \mathrm{~A})$ & $1.887(4)$ \\
\hline $\mathrm{O}(1 \mathrm{~A})-\mathrm{C}(11 \mathrm{~A})$ & $1.343(4)$ \\
\hline $\mathrm{O}(1 \mathrm{~A})-\mathrm{C}(1 \mathrm{~A})$ & $1.473(5)$ \\
\hline $\mathrm{O}(2 \mathrm{~A})-\mathrm{C}(11 \mathrm{~A})$ & $1.205(5)$ \\
\hline $\mathrm{C}(1 \mathrm{~A})-\mathrm{C}(2 \mathrm{~A})$ & $1.513(6)$ \\
\hline$C(1 \mathrm{~A})-\mathrm{C}(10 \mathrm{~A})$ & $1.520(6)$ \\
\hline$C(2 A)-C(7 A)$ & $1.386(6)$ \\
\hline $\mathrm{C}(2 \mathrm{~A})-\mathrm{C}(3 \mathrm{~A})$ & $1.406(7)$ \\
\hline$C(3 A)-C(4 A)$ & $1.391(7)$ \\
\hline $\mathrm{C}(4 \mathrm{~A})-\mathrm{C}(5 \mathrm{~A})$ & $1.386(8)$ \\
\hline$C(5 A)-C(6 A)$ & $1.378(8)$ \\
\hline$C(6 A)-C(7 A)$ & $1.393(7)$ \\
\hline$C(7 A)-C(8 A)$ & $1.522(7)$ \\
\hline $\mathrm{C}(8 \mathrm{~A})-\mathrm{C}(9 \mathrm{~A})$ & $1.517(7)$ \\
\hline$C(9 A)-C(10 A)$ & $1.537(6)$ \\
\hline$C(10 A)-C(18 A)$ & $1.514(6)$ \\
\hline $\mathrm{C}(11 \mathrm{~A})-\mathrm{C}(12 \mathrm{~A})$ & $1.493(6)$ \\
\hline$C(12 A)-C(17 A)$ & $1.383(6)$ \\
\hline $\mathrm{C}(12 \mathrm{~A})-\mathrm{C}(13 \mathrm{~A})$ & $1.392(5)$ \\
\hline$C(13 \mathrm{~A})-\mathrm{C}(14 \mathrm{~A})$ & $1.377(6)$ \\
\hline $\mathrm{C}(14 \mathrm{~A})-\mathrm{C}(15 \mathrm{~A})$ & $1.384(7)$ \\
\hline$C(15 A)-C(16 A)$ & $1.383(6)$ \\
\hline$C(16 A)-C(17 A)$ & $1.386(6)$ \\
\hline $\mathrm{C}(18 \mathrm{~A})-\mathrm{C}(19 \mathrm{~A})$ & $1.377(6)$ \\
\hline$C(18 \mathrm{~A})-\mathrm{C}(23 \mathrm{~A})$ & $1.398(6)$ \\
\hline$C(19 A)-C(20 A)$ & $1.391(7)$ \\
\hline$C(20 A)-C(21 A)$ & $1.388(7)$ \\
\hline$C(21 A)-C(22 A)$ & $1.373(7)$ \\
\hline$C(22 A)-C(23 A)$ & $1.390(7)$ \\
\hline $\mathrm{Br}(1 \mathrm{~B})-\mathrm{C}(15 \mathrm{~B})$ & $1.903(4)$ \\
\hline $\mathrm{O}(1 \mathrm{~B})-\mathrm{C}(11 \mathrm{~B})$ & $1.331(5)$ \\
\hline $\mathrm{O}(1 \mathrm{~B})-\mathrm{C}(1 \mathrm{~B})$ & $1.481(4)$ \\
\hline $\mathrm{O}(2 \mathrm{~B})-\mathrm{C}(11 \mathrm{~B})$ & $1.216(5)$ \\
\hline $\mathrm{C}(1 \mathrm{~B})-\mathrm{C}(2 \mathrm{~B})$ & $1.498(6)$ \\
\hline
\end{tabular}




\begin{tabular}{|c|c|}
\hline$C(1 B)-C(10 B)$ & $1.524(6)$ \\
\hline$C(2 B)-C(3 B)$ & $1.385(7)$ \\
\hline $\mathrm{C}(2 \mathrm{~B})-\mathrm{C}(7 \mathrm{~B})$ & $1.397(6)$ \\
\hline$C(3 B)-C(4 B)$ & $1.380(7)$ \\
\hline$C(4 B)-C(5 B)$ & $1.393(8)$ \\
\hline $\mathrm{C}(5 \mathrm{~B})-\mathrm{C}(6 \mathrm{~B})$ & $1.375(8)$ \\
\hline $\mathrm{C}(6 \mathrm{~B})-\mathrm{C}(7 \mathrm{~B})$ & $1.403(7)$ \\
\hline $\mathrm{C}(7 \mathrm{~B})-\mathrm{C}(8 \mathrm{~B})$ & $1.506(7)$ \\
\hline $\mathrm{C}(8 \mathrm{~B})-\mathrm{C}(9 \mathrm{~B})$ & $1.524(6)$ \\
\hline $\mathrm{C}(9 \mathrm{~B})-\mathrm{C}(10 \mathrm{~B})$ & $1.526(6)$ \\
\hline$C(10 B)-C(18 B)$ & $1.511(6)$ \\
\hline$C(11 B)-C(12 B)$ & $1.490(5)$ \\
\hline $\mathrm{C}(12 \mathrm{~B})-\mathrm{C}(17 \mathrm{~B})$ & $1.381(6)$ \\
\hline$C(12 B)-C(13 B)$ & $1.398(6)$ \\
\hline$C(13 B)-C(14 B)$ & $1.387(6)$ \\
\hline$C(14 B)-C(15 B)$ & $1.376(6)$ \\
\hline$C(15 B)-C(16 B)$ & $1.381(6)$ \\
\hline$C(16 B)-C(17 B)$ & $1.386(6)$ \\
\hline $\mathrm{C}(18 \mathrm{~B})-\mathrm{C}(23 \mathrm{~B})$ & $1.391(6)$ \\
\hline$C(18 B)-C(19 B)$ & $1.392(6)$ \\
\hline$C(19 B)-C(20 B)$ & $1.384(7)$ \\
\hline $\mathrm{C}(20 \mathrm{~B})-\mathrm{C}(21 \mathrm{~B})$ & $1.379(6)$ \\
\hline$C(21 B)-C(22 B)$ & $1.377(6)$ \\
\hline $\mathrm{C}(22 \mathrm{~B})-\mathrm{C}(23 \mathrm{~B})$ & $1.399(7)$ \\
\hline $\operatorname{Br}(1 \mathrm{C})-\mathrm{C}(15 \mathrm{C})$ & $1.893(4)$ \\
\hline $\mathrm{O}(1 \mathrm{C})-\mathrm{C}(11 \mathrm{C})$ & $1.333(5)$ \\
\hline $\mathrm{O}(1 \mathrm{C})-\mathrm{C}(1 \mathrm{C})$ & $1.474(5)$ \\
\hline $\mathrm{O}(2 \mathrm{C})-\mathrm{C}(11 \mathrm{C})$ & $1.216(5)$ \\
\hline$C(1 C)-C(2 C)$ & $1.525(6)$ \\
\hline$C(1 C)-C(10 C)$ & $1.526(6)$ \\
\hline$C(2 C)-C(3 C)$ & $1.391(6)$ \\
\hline$C(2 C)-C(7 C)$ & $1.395(6)$ \\
\hline$C(3 C)-C(4 C)$ & $1.384(6)$ \\
\hline$C(4 C)-C(5 C)$ & $1.388(7)$ \\
\hline$C(5 C)-C(6 C)$ & $1.374(7)$ \\
\hline$C(6 C)-C(7 C)$ & $1.394(6)$ \\
\hline
\end{tabular}




\begin{tabular}{|c|c|}
\hline $\mathrm{C}(7 \mathrm{C})-\mathrm{C}(8 \mathrm{C})$ & $1.505(6)$ \\
\hline $\mathrm{C}(8 \mathrm{C})-\mathrm{C}(9 \mathrm{C})$ & $1.532(6)$ \\
\hline$C(9 C)-C(10 C)$ & $1.536(6)$ \\
\hline$C(10 C)-C(18 C)$ & $1.518(6)$ \\
\hline$C(11 C)-C(12 C)$ & $1.489(6)$ \\
\hline$C(12 C)-C(13 C)$ & $1.370(6)$ \\
\hline$C(12 C)-C(17 C)$ & $1.406(6)$ \\
\hline$C(13 C)-C(14 C)$ & $1.386(7)$ \\
\hline$C(14 C)-C(15 C)$ & $1.397(6)$ \\
\hline$C(15 C)-C(16 C)$ & $1.387(6)$ \\
\hline$C(16 C)-C(17 C)$ & $1.382(6)$ \\
\hline$C(18 C)-C(23 C)$ & $1.387(7)$ \\
\hline$C(18 C)-C(19 C)$ & $1.385(7)$ \\
\hline$C(19 C)-C(20 C)$ & $1.381(7)$ \\
\hline$C(20 C)-C(21 C)$ & $1.377(8)$ \\
\hline$C(21 C)-C(22 C)$ & $1.390(8)$ \\
\hline$C(22 C)-C(23 C)$ & $1.378(7)$ \\
\hline $\mathrm{Br}(1 \mathrm{D})-\mathrm{C}(15 \mathrm{D})$ & $1.889(5)$ \\
\hline $\mathrm{O}(1 \mathrm{D})-\mathrm{C}(11 \mathrm{D})$ & $1.345(5)$ \\
\hline $\mathrm{O}(1 \mathrm{D})-\mathrm{C}(1 \mathrm{D})$ & $1.461(5)$ \\
\hline $\mathrm{O}(2 \mathrm{D})-\mathrm{C}(11 \mathrm{D})$ & $1.215(5)$ \\
\hline$C(1 D)-C(2 D)$ & $1.527(6)$ \\
\hline C(1D)-C(10D) & $1.529(6)$ \\
\hline$C(2 D)-C(7 D)$ & $1.392(6)$ \\
\hline $\mathrm{C}(2 \mathrm{D})-\mathrm{C}(3 \mathrm{D})$ & $1.409(6)$ \\
\hline$C(3 D)-C(4 D)$ & $1.385(6)$ \\
\hline$C(4 D)-C(5 D)$ & $1.383(8)$ \\
\hline$C(5 D)-C(6 D)$ & $1.375(7)$ \\
\hline C(6D)-C(7D) & $1.401(6)$ \\
\hline $\mathrm{C}(7 \mathrm{D})-\mathrm{C}(8 \mathrm{E})$ & $1.508(7)$ \\
\hline $\mathrm{C}(8 \mathrm{D})-\mathrm{C}(10 \mathrm{D})$ & $1.523(6)$ \\
\hline $\mathrm{C}(8 \mathrm{D})-\mathrm{C}(8 \mathrm{E})$ & $1.526(6)$ \\
\hline$C(10 D)-C(18 D)$ & $1.516(6)$ \\
\hline$C(11 D)-C(12 D)$ & $1.476(6)$ \\
\hline$C(12 D)-C(13 D)$ & $1.392(6)$ \\
\hline$C(12 D)-C(17 D)$ & $1.397(6)$ \\
\hline
\end{tabular}




\begin{tabular}{|c|c|}
\hline$C(13 D)-C(14 D)$ & $1.381(7)$ \\
\hline$C(14 D)-C(15 D)$ & $1.387(6)$ \\
\hline$C(15 D)-C(16 D)$ & $1.385(6)$ \\
\hline$C(16 D)-C(17 D)$ & $1.384(6)$ \\
\hline C(18D)-C(19D) & $1.387(6)$ \\
\hline$C(18 D)-C(23 D)$ & $1.389(6)$ \\
\hline$C(19 D)-C(20 D)$ & $1.386(6)$ \\
\hline$C(20 D)-C(21 D)$ & $1.378(8)$ \\
\hline$C(21 D)-C(22 D)$ & $1.374(8)$ \\
\hline$C(22 D)-C(23 D)$ & $1.393(6)$ \\
\hline $\mathrm{C}(11 \mathrm{~A})-\mathrm{O}(1 \mathrm{~A})-\mathrm{C}(1 \mathrm{~A})$ & $117.0(3)$ \\
\hline $\mathrm{O}(1 \mathrm{~A})-\mathrm{C}(1 \mathrm{~A})-\mathrm{C}(2 \mathrm{~A})$ & $108.7(3)$ \\
\hline $\mathrm{O}(1 \mathrm{~A})-\mathrm{C}(1 \mathrm{~A})-\mathrm{C}(10 \mathrm{~A})$ & $106.4(3)$ \\
\hline$C(2 A)-C(1 A)-C(10 A)$ & $113.3(3)$ \\
\hline $\mathrm{C}(7 \mathrm{~A})-\mathrm{C}(2 \mathrm{~A})-\mathrm{C}(3 \mathrm{~A})$ & $119.5(4)$ \\
\hline$C(7 A)-C(2 A)-C(1 A)$ & 121.1(4) \\
\hline $\mathrm{C}(3 \mathrm{~A})-\mathrm{C}(2 \mathrm{~A})-\mathrm{C}(1 \mathrm{~A})$ & 119.3(4) \\
\hline $\mathrm{C}(4 \mathrm{~A})-\mathrm{C}(3 \mathrm{~A})-\mathrm{C}(2 \mathrm{~A})$ & $120.4(5)$ \\
\hline$C(5 A)-C(4 A)-C(3 A)$ & $119.4(5)$ \\
\hline$C(6 A)-C(5 A)-C(4 A)$ & $120.3(5)$ \\
\hline$C(5 A)-C(6 A)-C(7 A)$ & $120.9(5)$ \\
\hline$C(2 A)-C(7 A)-C(6 A)$ & $119.5(5)$ \\
\hline $\mathrm{C}(2 \mathrm{~A})-\mathrm{C}(7 \mathrm{~A})-\mathrm{C}(8 \mathrm{~A})$ & $121.6(4)$ \\
\hline $\mathrm{C}(6 \mathrm{~A})-\mathrm{C}(7 \mathrm{~A})-\mathrm{C}(8 \mathrm{~A})$ & $118.9(4)$ \\
\hline $\mathrm{C}(9 \mathrm{~A})-\mathrm{C}(8 \mathrm{~A})-\mathrm{C}(7 \mathrm{~A})$ & 113.2(3) \\
\hline $\mathrm{C}(8 \mathrm{~A})-\mathrm{C}(9 \mathrm{~A})-\mathrm{C}(10 \mathrm{~A})$ & $109.6(4)$ \\
\hline$C(18 \mathrm{~A})-\mathrm{C}(10 \mathrm{~A})-\mathrm{C}(1 \mathrm{~A})$ & 114.1(3) \\
\hline $\mathrm{C}(18 \mathrm{~A})-\mathrm{C}(10 \mathrm{~A})-\mathrm{C}(9 \mathrm{~A})$ & $115.0(4)$ \\
\hline$C(1 \mathrm{~A})-\mathrm{C}(10 \mathrm{~A})-\mathrm{C}(9 \mathrm{~A})$ & $108.8(4)$ \\
\hline $\mathrm{O}(2 \mathrm{~A})-\mathrm{C}(11 \mathrm{~A})-\mathrm{O}(1 \mathrm{~A})$ & $124.3(4)$ \\
\hline $\mathrm{O}(2 \mathrm{~A})-\mathrm{C}(11 \mathrm{~A})-\mathrm{C}(12 \mathrm{~A})$ & $123.9(3)$ \\
\hline $\mathrm{O}(1 \mathrm{~A})-\mathrm{C}(11 \mathrm{~A})-\mathrm{C}(12 \mathrm{~A})$ & $111.9(3)$ \\
\hline$C(17 A)-C(12 A)-C(13 A)$ & 119.1(4) \\
\hline$C(17 A)-C(12 A)-C(11 A)$ & $123.4(3)$ \\
\hline $\mathrm{C}(13 \mathrm{~A})-\mathrm{C}(12 \mathrm{~A})-\mathrm{C}(11 \mathrm{~A})$ & $117.4(4)$ \\
\hline
\end{tabular}




\begin{tabular}{ll} 
C(14A)-C(13A)-C(12A) & $120.7(4)$ \\
C(13A)-C(14A)-C(15A) & $119.4(4)$ \\
C(16A)-C(15A)-C(14A) & $120.8(4)$ \\
C(16A)-C(15A)-Br(1A) & $119.3(4)$ \\
C(14A)-C(15A)-Br(1A) & $119.8(3)$ \\
C(15A)-C(16A)-C(17A) & $119.2(4)$ \\
C(12A)-C(17A)-C(16A) & $120.7(4)$ \\
C(19A)-C(18A)-C(23A) & $118.5(4)$ \\
C(19A)-C(18A)-C(10A) & $118.8(4)$ \\
C(23A)-C(18A)-C(10A) & $122.7(4)$ \\
C(18A)-C(19A)-C(20A) & $121.8(4)$ \\
C(21A)-C(20A)-C(19A) & $119.2(5)$ \\
C(22A)-C(21A)-C(20A) & $119.5(5)$ \\
C(21A)-C(22A)-C(23A) & $121.2(4)$ \\
C(22A)-C(23A)-C(18A) & $119.7(4)$ \\
C(11B)-O(1B)-C(1B) & $118.7(3)$ \\
O(1B)-C(1B)-C(2B) & $106.8(3)$ \\
O(1B)-C(1B)-C(10B) & $107.1(3)$ \\
C(2B)-C(1B)-C(10B) & $113.7(3)$ \\
C(3B)-C(2B)-C(7B) & $120.0(4)$ \\
C(3B)-C(2B)-C(1B) & $119.1(4)$ \\
C(7B)-C(2B)-C(1B) & $120.9(4)$ \\
C(4B)-C(3B)-C(2B) & $121.7(5)$ \\
C(3B)-C(4B)-C(5B) & $118.9(5)$ \\
C(6B)-C(5B)-C(4B) & $119.8(5)$ \\
C(5B)-C(6B)-C(7B) & $121.9(5)$ \\
C(2B)-C(7B)-C(6B) & $117.7(5)$ \\
C(2B)-C(7B)-C(8B) & $122.0(4)$ \\
C(6B)-C(7B)-C(8B) & $120.3(4)$ \\
C(7B)-C(8B)-C(9B) & $113.1(4)$ \\
C(18B)-C(10B) & $109.8(4)$ \\
\hline
\end{tabular}




\begin{tabular}{|c|c|}
\hline $\mathrm{O}(1 \mathrm{~B})-\mathrm{C}(11 \mathrm{~B})-\mathrm{C}(12 \mathrm{~B})$ & $112.1(3)$ \\
\hline$C(17 B)-C(12 B)-C(13 B)$ & $119.7(4)$ \\
\hline$C(17 B)-C(12 B)-C(11 B)$ & $120.7(4)$ \\
\hline$C(13 B)-C(12 B)-C(11 B)$ & $119.4(4)$ \\
\hline $\mathrm{C}(14 \mathrm{~B})-\mathrm{C}(13 \mathrm{~B})-\mathrm{C}(12 \mathrm{~B})$ & $120.6(4)$ \\
\hline $\mathrm{C}(15 \mathrm{~B})-\mathrm{C}(14 \mathrm{~B})-\mathrm{C}(13 \mathrm{~B})$ & $118.4(4)$ \\
\hline$C(14 B)-C(15 B)-C(16 B)$ & $121.9(4)$ \\
\hline$C(14 B)-C(15 B)-B r(1 B)$ & $119.6(3)$ \\
\hline$C(16 B)-C(15 B)-B r(1 B)$ & $118.5(3)$ \\
\hline$C(15 B)-C(16 B)-C(17 B)$ & $119.4(4)$ \\
\hline$C(12 B)-C(17 B)-C(16 B)$ & $119.9(4)$ \\
\hline$C(23 B)-C(18 B)-C(19 B)$ & $117.7(4)$ \\
\hline $\mathrm{C}(23 \mathrm{~B})-\mathrm{C}(18 \mathrm{~B})-\mathrm{C}(10 \mathrm{~B})$ & $122.6(4)$ \\
\hline $\mathrm{C}(19 \mathrm{~B})-\mathrm{C}(18 \mathrm{~B})-\mathrm{C}(10 \mathrm{~B})$ & $119.8(4)$ \\
\hline$C(20 B)-C(19 B)-C(18 B)$ & $121.8(4)$ \\
\hline$C(21 B)-C(20 B)-C(19 B)$ & $119.9(4)$ \\
\hline$C(22 B)-C(21 B)-C(20 B)$ & $119.5(5)$ \\
\hline $\mathrm{C}(21 \mathrm{~B})-\mathrm{C}(22 \mathrm{~B})-\mathrm{C}(23 \mathrm{~B})$ & $120.6(4)$ \\
\hline $\mathrm{C}(18 \mathrm{~B})-\mathrm{C}(23 \mathrm{~B})-\mathrm{C}(22 \mathrm{~B})$ & $120.5(4)$ \\
\hline $\mathrm{C}(11 \mathrm{C})-\mathrm{O}(1 \mathrm{C})-\mathrm{C}(1 \mathrm{C})$ & $117.1(3)$ \\
\hline $\mathrm{O}(1 \mathrm{C})-\mathrm{C}(1 \mathrm{C})-\mathrm{C}(2 \mathrm{C})$ & $108.8(3)$ \\
\hline $\mathrm{O}(1 \mathrm{C})-\mathrm{C}(1 \mathrm{C})-\mathrm{C}(10 \mathrm{C})$ & $105.8(3)$ \\
\hline$C(2 C)-C(1 C)-C(10 C)$ & $113.0(4)$ \\
\hline$C(3 C)-C(2 C)-C(7 C)$ & $120.3(4)$ \\
\hline$C(3 C)-C(2 C)-C(1 C)$ & $119.4(4)$ \\
\hline$C(7 C)-C(2 C)-C(1 C)$ & $120.3(4)$ \\
\hline$C(4 C)-C(3 C)-C(2 C)$ & $120.5(5)$ \\
\hline$C(3 C)-C(4 C)-C(5 C)$ & $119.6(4)$ \\
\hline$C(6 C)-C(5 C)-C(4 C)$ & $119.7(4)$ \\
\hline$C(5 C)-C(6 C)-C(7 C)$ & $121.8(5)$ \\
\hline$C(6 C)-C(7 C)-C(2 C)$ & $118.0(4)$ \\
\hline$C(6 C)-C(7 C)-C(8 C)$ & $119.6(4)$ \\
\hline$C(2 C)-C(7 C)-C(8 C)$ & $122.3(4)$ \\
\hline $\mathrm{C}(7 \mathrm{C})-\mathrm{C}(8 \mathrm{C})-\mathrm{C}(9 \mathrm{C})$ & $114.1(4)$ \\
\hline$C(8 C)-C(9 C)-C(10 C)$ & $109.3(3)$ \\
\hline$C(18 C)-C(10 C)-C(1 C)$ & $112.4(4)$ \\
\hline
\end{tabular}




\begin{tabular}{|c|c|}
\hline$C(18 C)-C(10 C)-C(9 C)$ & $115.6(3)$ \\
\hline$C(1 C)-C(10 C)-C(9 C)$ & $109.4(3)$ \\
\hline $\mathrm{O}(2 \mathrm{C})-\mathrm{C}(11 \mathrm{C})-\mathrm{O}(1 \mathrm{C})$ & $124.3(4)$ \\
\hline $\mathrm{O}(2 \mathrm{C})-\mathrm{C}(11 \mathrm{C})-\mathrm{C}(12 \mathrm{C})$ & $122.4(4)$ \\
\hline $\mathrm{O}(1 \mathrm{C})-\mathrm{C}(11 \mathrm{C})-\mathrm{C}(12 \mathrm{C})$ & $113.3(3)$ \\
\hline$C(13 C)-C(12 C)-C(17 C)$ & $119.2(4)$ \\
\hline$C(13 C)-C(12 C)-C(11 C)$ & $118.0(4)$ \\
\hline$C(17 C)-C(12 C)-C(11 C)$ & $122.7(4)$ \\
\hline$C(12 C)-C(13 C)-C(14 C)$ & $122.1(4)$ \\
\hline$C(13 C)-C(14 C)-C(15 C)$ & $117.8(4)$ \\
\hline$C(16 C)-C(15 C)-C(14 C)$ & $121.4(4)$ \\
\hline$C(16 C)-C(15 C)-B r(1 C)$ & $119.8(3)$ \\
\hline$C(14 C)-C(15 C)-B r(1 C)$ & $118.7(3)$ \\
\hline$C(17 C)-C(16 C)-C(15 C)$ & $119.4(4)$ \\
\hline$C(16 C)-C(17 C)-C(12 C)$ & $120.0(4)$ \\
\hline$C(23 C)-C(18 C)-C(19 C)$ & $118.2(4)$ \\
\hline$C(23 C)-C(18 C)-C(10 C)$ & $122.4(4)$ \\
\hline$C(19 C)-C(18 C)-C(10 C)$ & $119.4(4)$ \\
\hline$C(20 C)-C(19 C)-C(18 C)$ & $121.6(5)$ \\
\hline$C(21 C)-C(20 C)-C(19 C)$ & $119.2(5)$ \\
\hline$C(20 C)-C(21 C)-C(22 C)$ & $120.4(5)$ \\
\hline$C(23 C)-C(22 C)-C(21 C)$ & $119.5(5)$ \\
\hline$C(22 C)-C(23 C)-C(18 C)$ & $121.0(5)$ \\
\hline$C(11 D)-O(1 D)-C(1 D)$ & $116.9(3)$ \\
\hline $\mathrm{O}(1 \mathrm{D})-\mathrm{C}(1 \mathrm{D})-\mathrm{C}(2 \mathrm{D})$ & $109.1(3)$ \\
\hline $\mathrm{O}(1 \mathrm{D})-\mathrm{C}(1 \mathrm{D})-\mathrm{C}(10 \mathrm{D})$ & $106.4(3)$ \\
\hline$C(2 D)-C(1 D)-C(10 D)$ & $112.5(3)$ \\
\hline$C(7 D)-C(2 D)-C(3 D)$ & $120.9(4)$ \\
\hline$C(7 D)-C(2 D)-C(1 D)$ & $120.8(4)$ \\
\hline$C(3 D)-C(2 D)-C(1 D)$ & $118.4(4)$ \\
\hline$C(4 D)-C(3 D)-C(2 D)$ & $119.1(5)$ \\
\hline$C(5 D)-C(4 D)-C(3 D)$ & $120.7(5)$ \\
\hline$C(6 D)-C(5 D)-C(4 D)$ & $119.6(5)$ \\
\hline$C(5 D)-C(6 D)-C(7 D)$ & $121.8(5)$ \\
\hline$C(2 D)-C(7 D)-C(6 D)$ & $117.9(4)$ \\
\hline$C(2 D)-C(7 D)-C(8 E)$ & $121.9(4)$ \\
\hline
\end{tabular}




\begin{tabular}{|c|c|}
\hline$C(6 D)-C(7 D)-C(8 E)$ & $120.2(4)$ \\
\hline $\mathrm{C}(10 \mathrm{D})-\mathrm{C}(8 \mathrm{D})-\mathrm{C}(8 \mathrm{E})$ & $109.0(4)$ \\
\hline$C(7 D)-C(8 E)-C(8 D)$ & $113.4(4)$ \\
\hline$C(18 D)-C(10 D)-C(8 D)$ & $115.4(4)$ \\
\hline$C(18 D)-C(10 D)-C(1 D)$ & $111.7(3)$ \\
\hline $\mathrm{C}(8 \mathrm{D})-\mathrm{C}(10 \mathrm{D})-\mathrm{C}(1 \mathrm{D})$ & $109.5(3)$ \\
\hline $\mathrm{O}(2 \mathrm{D})-\mathrm{C}(11 \mathrm{D})-\mathrm{O}(1 \mathrm{D})$ & $124.0(4)$ \\
\hline $\mathrm{O}(2 \mathrm{D})-\mathrm{C}(11 \mathrm{D})-\mathrm{C}(12 \mathrm{D})$ & $123.3(4)$ \\
\hline $\mathrm{O}(1 \mathrm{D})-\mathrm{C}(11 \mathrm{D})-\mathrm{C}(12 \mathrm{D})$ & $112.7(4)$ \\
\hline$C(13 D)-C(12 D)-C(17 D)$ & $118.2(4)$ \\
\hline$C(13 D)-C(12 D)-C(11 D)$ & $117.5(4)$ \\
\hline$C(17 D)-C(12 D)-C(11 D)$ & $124.3(4)$ \\
\hline$C(14 D)-C(13 D)-C(12 D)$ & $122.1(4)$ \\
\hline$C(13 D)-C(14 D)-C(15 D)$ & $118.3(4)$ \\
\hline$C(16 D)-C(15 D)-C(14 D)$ & $121.3(4)$ \\
\hline$C(16 D)-C(15 D)-B r(1 D)$ & $119.6(3)$ \\
\hline$C(14 D)-C(15 D)-B r(1 D)$ & 119.1(3) \\
\hline$C(17 D)-C(16 D)-C(15 D)$ & $119.4(4)$ \\
\hline$C(16 D)-C(17 D)-C(12 D)$ & $120.7(4)$ \\
\hline$C(19 D)-C(18 D)-C(23 D)$ & $118.2(4)$ \\
\hline$C(19 D)-C(18 D)-C(10 D)$ & $119.8(4)$ \\
\hline$C(23 D)-C(18 D)-C(10 D)$ & $122.0(4)$ \\
\hline$C(20 D)-C(19 D)-C(18 D)$ & $121.0(5)$ \\
\hline$C(21 D)-C(20 D)-C(19 D)$ & $120.2(5)$ \\
\hline$C(22 D)-C(21 D)-C(20 D)$ & $119.7(4)$ \\
\hline$C(21 D)-C(22 D)-C(23 D)$ & $120.2(5)$ \\
\hline $\mathrm{C}(18 \mathrm{D})-\mathrm{C}(23 \mathrm{D})-\mathrm{C}(22 \mathrm{D})$ & $120.7(4)$ \\
\hline
\end{tabular}

Symmetry transformations used to generate equivalent atoms: 
Table 5. Anisotropic displacement parameters $\left(\AA^{2} \times 10^{3}\right)$ for 14 . The anisotropic displacement factor exponent takes the form: $-2 p^{2}\left[h^{2} a^{* 2} U^{11}+\ldots+2 h k a^{*} b^{*} U^{12}\right]$

\begin{tabular}{|c|c|c|c|c|c|c|}
\hline & $\mathrm{U}^{11}$ & $\mathrm{U}^{22}$ & $\mathrm{U}^{33}$ & $\mathrm{U}^{23}$ & $\mathrm{U}^{13}$ & $\mathrm{U}^{12}$ \\
\hline $\operatorname{Br}(1 \mathrm{~A})$ & $61(1)$ & $43(1)$ & $34(1)$ & $22(1)$ & $2(1)$ & $-5(1)$ \\
\hline $\mathrm{O}(1 \mathrm{~A})$ & $23(2)$ & $26(2)$ & $28(2)$ & $16(1)$ & $5(1)$ & $7(1)$ \\
\hline $\mathrm{O}(2 \mathrm{~A})$ & $27(2)$ & $46(2)$ & $37(2)$ & $21(2)$ & $6(1)$ & $11(2)$ \\
\hline$C(1 \mathrm{~A})$ & $24(2)$ & $29(2)$ & $27(2)$ & $15(2)$ & $0(2)$ & $-2(2)$ \\
\hline $\mathrm{C}(2 \mathrm{~A})$ & $35(3)$ & $29(3)$ & $27(2)$ & $13(2)$ & $5(2)$ & $-4(2)$ \\
\hline $\mathrm{C}(3 \mathrm{~A})$ & $42(3)$ & $33(3)$ & $31(3)$ & $16(2)$ & $7(2)$ & $-4(2)$ \\
\hline $\mathrm{C}(4 \mathrm{~A})$ & $67(4)$ & $39(3)$ & $36(3)$ & $12(3)$ & $22(3)$ & 2(3) \\
\hline $\mathrm{C}(5 \mathrm{~A})$ & $75(4)$ & $50(4)$ & $24(3)$ & $9(3)$ & $9(3)$ & $-17(3)$ \\
\hline$C(6 A)$ & $53(3)$ & $50(3)$ & 28(3) & 19(3) & $-4(2)$ & $-15(3)$ \\
\hline$C(7 A)$ & $37(3)$ & $40(3)$ & $32(3)$ & $21(2)$ & $-7(2)$ & $-19(2)$ \\
\hline$C(8 A)$ & $30(2)$ & $45(3)$ & $36(3)$ & $26(2)$ & $-6(2)$ & $-10(2)$ \\
\hline$C(9 A)$ & $25(2)$ & $36(3)$ & $47(3)$ & $27(2)$ & $0(2)$ & 2(2) \\
\hline$C(10 A)$ & $28(2)$ & $31(3)$ & $34(3)$ & $23(2)$ & $3(2)$ & $0(2)$ \\
\hline$C(11 \mathrm{~A})$ & $24(2)$ & $26(2)$ & $24(2)$ & $9(2)$ & $0(2)$ & $9(2)$ \\
\hline$C(12 A)$ & $27(2)$ & $27(2)$ & $23(2)$ & $11(2)$ & $3(2)$ & $8(2)$ \\
\hline$C(13 \mathrm{~A})$ & $37(3)$ & $31(3)$ & $34(3)$ & $16(2)$ & $5(2)$ & $16(2)$ \\
\hline$C(14 A)$ & $50(3)$ & $38(3)$ & $48(3)$ & 28(3) & $4(3)$ & $13(2)$ \\
\hline$C(15 A)$ & $39(3)$ & $31(3)$ & $26(2)$ & $12(2)$ & $-2(2)$ & $-5(2)$ \\
\hline$C(16 A)$ & $32(3)$ & $34(3)$ & $34(3)$ & $16(2)$ & $5(2)$ & $6(2)$ \\
\hline$C(17 \mathrm{~A})$ & $31(3)$ & $34(3)$ & $34(3)$ & $18(2)$ & $5(2)$ & $7(2)$ \\
\hline $\mathrm{C}(18 \mathrm{~A})$ & $29(2)$ & $24(2)$ & $36(3)$ & $19(2)$ & $0(2)$ & $3(2)$ \\
\hline$C(19 A)$ & $29(2)$ & $30(2)$ & $34(3)$ & $17(2)$ & $5(2)$ & $5(2)$ \\
\hline$C(20 \mathrm{~A})$ & $49(3)$ & $22(2)$ & $40(3)$ & $9(2)$ & $0(2)$ & $1(2)$ \\
\hline$C(21 \mathrm{~A})$ & $50(3)$ & $34(3)$ & $31(3)$ & $15(2)$ & $4(2)$ & $14(2)$ \\
\hline$C(22 \mathrm{~A})$ & $41(3)$ & $34(3)$ & $38(3)$ & $20(2)$ & $16(2)$ & $18(2)$ \\
\hline$C(23 \mathrm{~A})$ & $27(2)$ & $30(3)$ & $37(3)$ & $17(2)$ & $3(2)$ & $4(2)$ \\
\hline $\operatorname{Br}(1 \mathrm{~B})$ & $61(1)$ & $42(1)$ & $43(1)$ & $28(1)$ & 1(1) & $9(1)$ \\
\hline $\mathrm{O}(1 \mathrm{~B})$ & $25(2)$ & $31(2)$ & $33(2)$ & $21(2)$ & $4(1)$ & $5(1)$ \\
\hline $\mathrm{O}(2 \mathrm{~B})$ & $32(2)$ & $69(3)$ & $50(2)$ & $41(2)$ & $17(2)$ & $19(2)$ \\
\hline$C(1 B)$ & $24(2)$ & $32(2)$ & $27(2)$ & $18(2)$ & $-1(2)$ & $4(2)$ \\
\hline $\mathrm{C}(2 \mathrm{~B})$ & $31(2)$ & $26(2)$ & $21(2)$ & $12(2)$ & $-1(2)$ & $4(2)$ \\
\hline
\end{tabular}




\begin{tabular}{|c|c|c|c|c|c|c|}
\hline $\mathrm{C}(3 \mathrm{~B})$ & $41(3)$ & $38(3)$ & $33(3)$ & $17(2)$ & $2(2)$ & $-1(2)$ \\
\hline$C(4 B)$ & $52(3)$ & $36(3)$ & $40(3)$ & $13(3)$ & $-5(3)$ & $-5(2)$ \\
\hline $\mathrm{C}(5 \mathrm{~B})$ & $60(4)$ & $48(3)$ & $30(3)$ & $10(3)$ & 1(3) & $12(3)$ \\
\hline$C(6 B)$ & $36(3)$ & $52(3)$ & $32(3)$ & $20(3)$ & $5(2)$ & $5(3)$ \\
\hline $\mathrm{C}(7 \mathrm{~B})$ & $36(3)$ & $35(3)$ & $23(2)$ & $14(2)$ & $1(2)$ & $10(2)$ \\
\hline $\mathrm{C}(8 \mathrm{~B})$ & $28(2)$ & $40(3)$ & $31(2)$ & $20(2)$ & $3(2)$ & $4(2)$ \\
\hline $\mathrm{C}(9 \mathrm{~B})$ & $25(2)$ & $34(3)$ & $34(3)$ & $19(2)$ & $4(2)$ & $4(2)$ \\
\hline$C(10 B)$ & $24(2)$ & $24(2)$ & $31(2)$ & $16(2)$ & $2(2)$ & $4(2)$ \\
\hline $\mathrm{C}(11 \mathrm{~B})$ & $32(3)$ & $27(2)$ & $20(2)$ & $7(2)$ & $5(2)$ & $8(2)$ \\
\hline$C(12 B)$ & $27(2)$ & $23(2)$ & $21(2)$ & $10(2)$ & $2(2)$ & $2(2)$ \\
\hline$C(13 B)$ & $33(2)$ & $27(2)$ & $28(2)$ & $11(2)$ & $10(2)$ & $5(2)$ \\
\hline$C(14 B)$ & $40(3)$ & $30(3)$ & $26(2)$ & $14(2)$ & $6(2)$ & $3(2)$ \\
\hline$C(15 B)$ & $35(3)$ & $26(2)$ & $30(3)$ & $14(2)$ & $1(2)$ & $1(2)$ \\
\hline$C(16 B)$ & $33(3)$ & $36(3)$ & $36(3)$ & $18(2)$ & $4(2)$ & $8(2)$ \\
\hline $\mathrm{C}(17 \mathrm{~B})$ & $35(3)$ & $36(3)$ & $30(3)$ & $18(2)$ & $12(2)$ & $3(2)$ \\
\hline $\mathrm{C}(18 \mathrm{~B})$ & $27(2)$ & $22(2)$ & $32(2)$ & $16(2)$ & $3(2)$ & $1(2)$ \\
\hline$C(19 B)$ & $29(2)$ & $30(3)$ & $34(3)$ & $11(2)$ & $-3(2)$ & $3(2)$ \\
\hline$C(20 B)$ & $29(3)$ & $37(3)$ & $40(3)$ & $12(2)$ & $4(2)$ & $6(2)$ \\
\hline$C(21 B)$ & $34(3)$ & $33(3)$ & $33(3)$ & $10(2)$ & $4(2)$ & $8(2)$ \\
\hline $\mathrm{C}(22 \mathrm{~B})$ & $39(3)$ & $35(3)$ & $27(2)$ & $12(2)$ & $-7(2)$ & $4(2)$ \\
\hline$C(23 B)$ & $28(2)$ & $32(3)$ & $40(3)$ & $21(2)$ & $0(2)$ & $8(2)$ \\
\hline $\operatorname{Br}(1 \mathrm{C})$ & $60(1)$ & $39(1)$ & $34(1)$ & $13(1)$ & $8(1)$ & $14(1)$ \\
\hline $\mathrm{O}(1 \mathrm{C})$ & $24(2)$ & $27(2)$ & $23(2)$ & $6(1)$ & $-1(1)$ & $2(1)$ \\
\hline $\mathrm{O}(2 \mathrm{C})$ & $24(2)$ & $36(2)$ & $51(2)$ & $13(2)$ & $-2(2)$ & $2(1)$ \\
\hline $\mathrm{C}(1 \mathrm{C})$ & $22(2)$ & $24(2)$ & $30(2)$ & $11(2)$ & $7(2)$ & $3(2)$ \\
\hline $\mathrm{C}(2 \mathrm{C})$ & $26(2)$ & $30(2)$ & $32(3)$ & $16(2)$ & $12(2)$ & $8(2)$ \\
\hline$C(3 C)$ & $33(2)$ & $31(3)$ & $34(3)$ & $15(2)$ & $6(2)$ & $5(2)$ \\
\hline $\mathrm{C}(4 \mathrm{C})$ & $44(3)$ & $42(3)$ & $38(3)$ & $23(3)$ & $10(2)$ & $16(2)$ \\
\hline$C(5 C)$ & $61(4)$ & $33(3)$ & $43(3)$ & $22(3)$ & $12(3)$ & $10(3)$ \\
\hline$C(6 C)$ & $49(3)$ & $28(3)$ & $43(3)$ & $14(2)$ & $15(2)$ & $2(2)$ \\
\hline $\mathrm{C}(7 \mathrm{C})$ & $33(3)$ & $29(2)$ & $30(2)$ & $8(2)$ & $13(2)$ & $9(2)$ \\
\hline$C(8 C)$ & $34(3)$ & $30(3)$ & $32(3)$ & $10(2)$ & $4(2)$ & $1(2)$ \\
\hline$C(9 C)$ & $24(2)$ & $35(3)$ & $31(3)$ & $11(2)$ & $1(2)$ & $-1(2)$ \\
\hline$C(10 C)$ & $28(2)$ & $31(3)$ & $25(2)$ & $10(2)$ & $4(2)$ & $3(2)$ \\
\hline$C(11 C)$ & $24(2)$ & $26(2)$ & $31(3)$ & $14(2)$ & $0(2)$ & $-1(2)$ \\
\hline$C(12 C)$ & $25(2)$ & $22(2)$ & $32(2)$ & $13(2)$ & $1(2)$ & $-2(2)$ \\
\hline
\end{tabular}




\begin{tabular}{|c|c|c|c|c|c|c|}
\hline $\mathrm{C}(13 \mathrm{C})$ & $32(2)$ & $33(3)$ & $35(3)$ & $18(2)$ & $-6(2)$ & $0(2)$ \\
\hline$C(14 C)$ & $34(3)$ & $34(3)$ & $28(3)$ & $13(2)$ & $-5(2)$ & $-3(2)$ \\
\hline$C(15 C)$ & $35(3)$ & $29(2)$ & $29(2)$ & $16(2)$ & $6(2)$ & $4(2)$ \\
\hline$C(16 C)$ & $31(3)$ & $37(3)$ & $36(3)$ & $22(2)$ & $4(2)$ & $3(2)$ \\
\hline $\mathrm{C}(17 \mathrm{C})$ & $31(2)$ & $32(3)$ & $29(3)$ & $17(2)$ & $1(2)$ & $2(2)$ \\
\hline $\mathrm{C}(18 \mathrm{C})$ & $33(3)$ & $34(3)$ & $25(2)$ & $12(2)$ & $-2(2)$ & $-2(2)$ \\
\hline$C(19 C)$ & $40(3)$ & $45(3)$ & $33(3)$ & $19(2)$ & $2(2)$ & $1(2)$ \\
\hline$C(20 \mathrm{C})$ & $49(3)$ & $63(4)$ & $39(3)$ & $30(3)$ & $-5(3)$ & $-16(3)$ \\
\hline $\mathrm{C}(21 \mathrm{C})$ & $64(4)$ & $42(3)$ & $48(3)$ & $25(3)$ & $-24(3)$ & $-14(3)$ \\
\hline $\mathrm{C}(22 \mathrm{C})$ & $55(3)$ & $41(3)$ & $50(3)$ & $25(3)$ & $-11(3)$ & $2(3)$ \\
\hline $\mathrm{C}(23 \mathrm{C})$ & $40(3)$ & $38(3)$ & $45(3)$ & $22(3)$ & $-6(2)$ & $0(2)$ \\
\hline $\operatorname{Br}(1 D)$ & $61(1)$ & $34(1)$ & $31(1)$ & $10(1)$ & $-1(1)$ & $-9(1)$ \\
\hline $\mathrm{O}(1 \mathrm{D})$ & $23(2)$ & $22(2)$ & $26(2)$ & $6(1)$ & $4(1)$ & $1(1)$ \\
\hline $\mathrm{O}(2 \mathrm{D})$ & $22(2)$ & $40(2)$ & $43(2)$ & $8(2)$ & $9(1)$ & $0(1)$ \\
\hline$C(1 D)$ & $23(2)$ & $26(2)$ & $23(2)$ & $7(2)$ & $-2(2)$ & $-2(2)$ \\
\hline$C(2 D)$ & $34(3)$ & $24(2)$ & $24(2)$ & $8(2)$ & $-7(2)$ & $-8(2)$ \\
\hline$C(3 D)$ & $34(3)$ & $36(3)$ & $28(3)$ & $14(2)$ & $-2(2)$ & $-11(2)$ \\
\hline$C(4 D)$ & $55(3)$ & $44(3)$ & $38(3)$ & 21(3) & $-2(3)$ & $-14(3)$ \\
\hline$C(5 D)$ & $65(4)$ & $32(3)$ & $40(3)$ & $22(3)$ & $-9(3)$ & $-13(3)$ \\
\hline$C(6 D)$ & $57(3)$ & $30(3)$ & $38(3)$ & $17(2)$ & $-8(2)$ & $1(2)$ \\
\hline$C(7 D)$ & $35(3)$ & $28(2)$ & $29(2)$ & $13(2)$ & $-6(2)$ & $-2(2)$ \\
\hline$C(8 D)$ & $25(2)$ & $32(3)$ & $24(2)$ & $9(2)$ & $3(2)$ & $5(2)$ \\
\hline $\mathrm{C}(8 \mathrm{E})$ & $32(3)$ & $29(3)$ & $36(3)$ & $11(2)$ & $-4(2)$ & $8(2)$ \\
\hline$C(10 D)$ & $27(2)$ & $22(2)$ & $24(2)$ & $10(2)$ & $1(2)$ & $0(2)$ \\
\hline$C(11 D)$ & $25(3)$ & $29(2)$ & $27(2)$ & $11(2)$ & $6(2)$ & $3(2)$ \\
\hline$C(12 D)$ & $25(2)$ & $26(2)$ & $27(2)$ & $15(2)$ & $3(2)$ & $4(2)$ \\
\hline$C(13 D)$ & $24(2)$ & $40(3)$ & $35(3)$ & $17(2)$ & $6(2)$ & $2(2)$ \\
\hline$C(14 D)$ & $36(3)$ & $31(3)$ & $34(3)$ & $17(2)$ & $8(2)$ & $5(2)$ \\
\hline$C(15 D)$ & $39(3)$ & $25(2)$ & $26(2)$ & $14(2)$ & $4(2)$ & $4(2)$ \\
\hline$C(16 D)$ & $24(2)$ & $36(3)$ & $34(3)$ & $19(2)$ & $-1(2)$ & $-3(2)$ \\
\hline$C(17 D)$ & $28(2)$ & $27(2)$ & $31(3)$ & $13(2)$ & $4(2)$ & $4(2)$ \\
\hline$C(18 D)$ & $26(2)$ & $26(2)$ & $25(2)$ & $8(2)$ & $1(2)$ & $5(2)$ \\
\hline$C(19 D)$ & $33(3)$ & $49(3)$ & $34(3)$ & $23(2)$ & $9(2)$ & $16(2)$ \\
\hline$C(20 D)$ & $49(3)$ & $45(3)$ & $36(3)$ & $21(3)$ & $7(2)$ & $18(3)$ \\
\hline$C(21 D)$ & $72(4)$ & $40(3)$ & $48(3)$ & $31(3)$ & $25(3)$ & $25(3)$ \\
\hline$C(22 D)$ & $62(4)$ & $32(3)$ & $50(3)$ & $23(3)$ & $14(3)$ & $0(3)$ \\
\hline
\end{tabular}


$\mathrm{C}(23 \mathrm{D}) \quad 34(3)$

32(3)

38(3)

19(2)

4(2)

3(2) 
Table 6. Hydrogen coordinates ( $\left.\times 10^{4}\right)$ and isotropic displacement parameters $\left(\AA^{2} \times 10^{3}\right)$ for 14.

\begin{tabular}{|c|c|c|c|c|}
\hline & $\mathrm{x}$ & $\mathrm{y}$ & $\mathrm{z}$ & $\mathrm{U}(\mathrm{eq})$ \\
\hline $\mathrm{H}(1 \mathrm{AA})$ & 8013 & 6298 & 4488 & 31 \\
\hline $\mathrm{H}(3 \mathrm{AA})$ & 8901 & 4880 & 3517 & 42 \\
\hline $\mathrm{H}(4 \mathrm{AA})$ & 8486 & 3867 & 2216 & 58 \\
\hline $\mathrm{H}(5 \mathrm{AA})$ & 5431 & 3843 & 1420 & 64 \\
\hline $\mathrm{H}(6 \mathrm{AA})$ & 2844 & 4823 & 1912 & 53 \\
\hline $\mathrm{H}(8 \mathrm{AA})$ & 2914 & 6520 & 3093 & 43 \\
\hline $\mathrm{H}(8 \mathrm{AB})$ & 1117 & 5812 & 3092 & 43 \\
\hline $\mathrm{H}(9 \mathrm{AA})$ & 2051 & 6189 & 4377 & 39 \\
\hline $\mathrm{H}(9 \mathrm{AB})$ & 1811 & 7065 & 4328 & 39 \\
\hline $\mathrm{H}(10 \mathrm{D})$ & 5769 & 7166 & 4214 & 34 \\
\hline $\mathrm{H}(13 \mathrm{D})$ & 8493 & 4246 & 5493 & 40 \\
\hline $\mathrm{H}(14 \mathrm{D})$ & 6932 & 3555 & 6163 & 50 \\
\hline $\mathrm{H}(16 \mathrm{D})$ & 1577 & 4896 & 6459 & 39 \\
\hline $\mathrm{H}(17 \mathrm{D})$ & 3035 & 5506 & 5704 & 38 \\
\hline $\mathrm{H}(19 \mathrm{D})$ & 8468 & 8004 & 5287 & 36 \\
\hline $\mathrm{H}(20 \mathrm{D})$ & 8966 & 9092 & 6550 & 47 \\
\hline $\mathrm{H}(21 \mathrm{D})$ & 6162 & 9256 & 7391 & 45 \\
\hline $\mathrm{H}(22 \mathrm{D})$ & 2950 & 8328 & 6961 & 42 \\
\hline $\mathrm{H}(23 \mathrm{D})$ & 2452 & 7237 & 5699 & 37 \\
\hline $\mathrm{H}(1 \mathrm{BA})$ & 12770 & 9329 & 9416 & 31 \\
\hline $\mathrm{H}(3 \mathrm{BA})$ & 13955 & 10795 & 10371 & 44 \\
\hline $\mathrm{H}(4 \mathrm{BA})$ & 13846 & 11854 & 11628 & 54 \\
\hline $\mathrm{H}(5 \mathrm{BA})$ & 10814 & 11806 & 12332 & 58 \\
\hline $\mathrm{H}(6 \mathrm{BA})$ & 8011 & 10705 & 11775 & 48 \\
\hline $\mathrm{H}(8 \mathrm{BA})$ & 5969 & 9599 & 10523 & 38 \\
\hline $\mathrm{H}(8 \mathrm{BB})$ & 7610 & 8973 & 10622 & 38 \\
\hline $\mathrm{H}(9 \mathrm{BA})$ & 6791 & 9202 & 9263 & 35 \\
\hline $\mathrm{H}(9 \mathrm{BB})$ & 6363 & 8332 & 9332 & 35 \\
\hline $\mathrm{H}(10 \mathrm{C})$ & 10292 & 8384 & 9606 & 30 \\
\hline $\mathrm{H}(13 \mathrm{C})$ & 13458 & 10323 & 7465 & 35 \\
\hline
\end{tabular}




\begin{tabular}{|c|c|c|c|c|}
\hline $\mathrm{H}(14 \mathrm{C})$ & 12102 & 11113 & 6861 & 38 \\
\hline $\mathrm{H}(16 \mathrm{C})$ & 6927 & 11630 & 8201 & 41 \\
\hline $\mathrm{H}(17 \mathrm{C})$ & 8191 & 10789 & 8764 & 39 \\
\hline $\mathrm{H}(19 \mathrm{C})$ & 12827 & 7629 & 8629 & 39 \\
\hline $\mathrm{H}(20 \mathrm{C})$ & 13054 & 6579 & 7379 & 44 \\
\hline $\mathrm{H}(21 \mathrm{C})$ & 10219 & 6313 & 6421 & 42 \\
\hline $\mathrm{H}(22 \mathrm{C})$ & 7195 & 7118 & 6721 & 41 \\
\hline $\mathrm{H}(23 \mathrm{C})$ & 6912 & 8155 & 7987 & 38 \\
\hline $\mathrm{H}(1 \mathrm{CA})$ & 19053 & 4322 & -373 & 31 \\
\hline $\mathrm{H}(3 \mathrm{CA})$ & 20495 & 3802 & 538 & 39 \\
\hline $\mathrm{H}(4 \mathrm{CA})$ & 20464 & 2691 & 882 & 46 \\
\hline $\mathrm{H}(5 \mathrm{CA})$ & 17352 & 1690 & 508 & 52 \\
\hline $\mathrm{H}(6 \mathrm{CA})$ & 14369 & 1789 & -227 & 48 \\
\hline $\mathrm{H}(8 \mathrm{CA})$ & 12286 & 2735 & -622 & 40 \\
\hline $\mathrm{H}(8 \mathrm{CB})$ & 13764 & 2398 & -1344 & 40 \\
\hline $\mathrm{H}(9 \mathrm{CA})$ & 13080 & 4134 & -377 & 38 \\
\hline $\mathrm{H}(9 \mathrm{CB})$ & 12536 & 3624 & -1296 & 38 \\
\hline $\mathrm{H}(10 \mathrm{~A})$ & 16459 & 3508 & -1422 & 35 \\
\hline $\mathrm{H}(13 \mathrm{~A})$ & 20167 & 6506 & 2255 & 39 \\
\hline $\mathrm{H}(14 \mathrm{~A})$ & 18939 & 7671 & 3287 & 40 \\
\hline $\mathrm{H}(16 \mathrm{~A})$ & 13125 & 7324 & 1994 & 39 \\
\hline $\mathrm{H}(17 \mathrm{~A})$ & 14360 & 6137 & 987 & 36 \\
\hline $\mathrm{H}(19 \mathrm{~A})$ & 18872 & 4441 & -1734 & 47 \\
\hline $\mathrm{H}(20 \mathrm{~A})$ & 19115 & 5527 & -2107 & 59 \\
\hline $\mathrm{H}(21 \mathrm{~A})$ & 16361 & 6459 & -1811 & 62 \\
\hline $\mathrm{H}(22 \mathrm{~A})$ & 13403 & 6318 & -1126 & 57 \\
\hline $\mathrm{H}(23 \mathrm{~A})$ & 13263 & 5261 & -717 & 48 \\
\hline $\mathrm{H}(1 \mathrm{DA})$ & 15180 & 11325 & 4207 & 31 \\
\hline $\mathrm{H}(3 \mathrm{DA})$ & 16323 & 11902 & 3303 & 40 \\
\hline $\mathrm{H}(4 \mathrm{DA})$ & 16240 & 13035 & 2988 & 55 \\
\hline $\mathrm{H}(5 \mathrm{DA})$ & 13411 & 13935 & 3373 & 53 \\
\hline $\mathrm{H}(6 \mathrm{DA})$ & 10744 & 13742 & 4116 & 50 \\
\hline $\mathrm{H}(8 \mathrm{DA})$ & 9066 & 11761 & 5088 & 34 \\
\hline $\mathrm{H}(8 \mathrm{DB})$ & 9233 & 11311 & 4170 & 34 \\
\hline $\mathrm{H}(8 \mathrm{EA})$ & 8701 & 12718 & 4504 & 41 \\
\hline $\mathrm{H}(8 \mathrm{~EB})$ & 10574 & 13057 & 5210 & 41 \\
\hline
\end{tabular}




$\begin{array}{lrrrr}\mathrm{H}(10 B) & 13057 & 12015 & 5248 & 29 \\ \mathrm{H}(13 \mathrm{~B}) & 15360 & 9167 & 1615 & 40 \\ \mathrm{H}(14 \mathrm{~B}) & 13715 & 7957 & 551 & 39 \\ \mathrm{H}(16 \mathrm{~B}) & 8089 & 8150 & 1660 & 36 \\ \mathrm{H}(17 \mathrm{~B}) & 9714 & 9394 & 2700 & 34 \\ \mathrm{H}(19 \mathrm{~B}) & 15549 & 11060 & 5449 & 43 \\ \mathrm{H}(20 \mathrm{~B}) & 15684 & 9949 & 5784 & 50 \\ \mathrm{H}(21 \mathrm{~B}) & 12601 & 8964 & 5497 & 57 \\ \mathrm{H}(22 \mathrm{~B}) & 9402 & 9081 & 4854 & 56 \\ \mathrm{H}(23 \mathrm{~B}) & 9235 & 10207 & 4532 & 40 \\ \end{array}$




\section{References}

${ }^{1}$ Stiles, M.; Miller, R. G. Can J. Chem. 1965, 43, 1599.

${ }^{2}$ Waymouth, R. M.; Millward, D. B.; Sammis, G. J. Org. Chem. 2000, 65, 3902.

${ }^{3}$ Caster, K. C.; Keck, C. G.; Walls, R. D. J. Org. Chem. 2001, 66, 2932.

${ }^{4}$ Jung, M. E.; Lam, P. Y.-S.; Mansuri, M. M.; Speltz, L. M. J. Org. Chem. 1985, 50, 1087.

${ }^{5}$ See, for example: a) Feng, C.-C.; Malay, N.; Sambaiah, T.; Cheng, C.-H. J. Org. Chem. 1999, 64, 3538.

b) Lautens, M.; Ma, S. J. Org. Chem. 1996, 61, 7246.

${ }^{6}$ Moinet, C.; Fiaud, J.-C. Tet. Lett. 1995, 36, 2051.

${ }^{7}$ This measurement is very different from that obtained in reference $4:[\alpha]_{D}{ }^{28}=+10(c=1.2$, EtOH $)$ for compound

2 reported to have $96 \%$ ee. 